\title{
EVALUATION OF RISKS AND WASTE CHARACTERIZATION REQUIREMENTS FOR THE TRANSURANIC WASTE EMPLACED IN WIPP DURING 1999
}

James K. Channell

Ben A. Walker

Environmental Evaluation Group

7007 Wyoming Boulevard NE, Suite F-2

Albuquerque, New Mexico 87109

and

P. O. Box 3149, 505 North Main Street

Carlsbad, New Mexico 88221

May 2000 


\section{DISCLAIMER}

This report was prepared as an account of work sponsored by an agency of the United States Government. Neither the United States Government nor any agency thereof, nor any of their employees, make any warranty, express or implied, or assumes any legal liability or responsibility for the accuracy, completeness, or usefulness of any information, apparatus, product, or process disclosed, or represents that its use would not infringe privately owned rights. Reference herein to any specific commercial product, process, or service by trade name, trademark, manufacturer, or otherwise does not necessarily constitute or imply its endorsement, recommendation, or favoring by the United States Government or any agency thereof. The views and opinions of authors expressed herein do not necessarily state or reflect those of the United States Government or any agency thereof. 


\section{DISCLAIMER}

Portions of this document may be illegible in electronic image products. Images are produced from the best available original document. 


\section{FOREWORD}

The purpose of the New Mexico Environmental Evaluation Group (EEG) is to conduct an independent technical evaluation of the Waste Isolation Pilot Plant (WIPP) Project to ensure the protection of the public health and safety and the environment. The WIPP Project, located in southeastern New Mexico, became operational in March 1999 for the disposal of transuranic (TRU) radioactive wastes generated by the national defense programs. The EEG was established in 1978 with funds provided by the U. S. Department of Energy (DOE) to the State of New Mexico. Public Law 100-456, the National Defense Authorization Act, Fiscal Year 1989, Section 1433, assigned EEG to the New Mexico Institute of Mining and Technology and continued the original contract DE-AC04-79AL10752 through DOE contract DE-ACO489AL58309. The National Defense Authorization Act for Fiscal Year 1994, Public Law 103160, and the National Defense Authorization Act for Fiscal Year 2000, Public Law 106-65, continued the authorization.

EEG performs independent technical analyses of the suitability of the proposed site; the design of the repository, its planned operation, and its long-term integrity; suitability and safety of the transportation systems; suitability of the Waste Acceptance Criteria and the compliance of the generator sites with them; and related subjects. These analyses include assessments of reports issued by the DOE and its contractors, other federal agencies and organizations, as they relate to the potential health, safety and environmental impacts from WIPP. Another important function of EEG is the independent environmental monitoring of background radioactivity in air, water, and soil, both on-site and off-site.

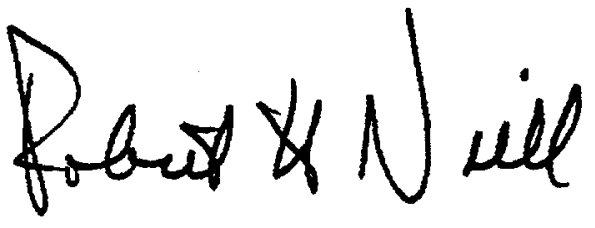

Robert H. Neill

Director 


\section{EEG STAFF}

Sally C. Ballard, B.S., Radiochemical Analyst

William T. Bartlett, Ph.D., Health Physicist

Radene Bradley, Secretary III

James K. Channell, Ph.D., CHP, Environmental Engineer/Health Physicist

Lokesh Chaturvedi, Ph.D., Deputy Director \& Engineering Geologist

Patricia D. Fairchild, Secretary III

Donald H. Gray, M.A., Laboratory Manager

Linda P. Kennedy, M.L.S., Librarian

Jim W. Kenney, M.S., Environmental Scientist/Supervisor

Lanny W. King, Assistant Environmental Technician

Robert H. Neill, M.S., Director

Dale Rucker, M.S., Environmental Engineer

Jill Shortencarier, Executive Assistant

Matthew K. Silva, Ph.D., Chemical Engineer

Susan Stokum, Administrative Secretary

Ben A. Walker, B.A., Quality Assurance Specialist

Brenda J. West, B.A., Administrative Officer 


\section{ACKNOWLEDGMENTS}

The authors appreciate the secretarial support of Susan Stokum, Patricia Fairchild and Jill Shortencarier through all the drafts, tables, and changes.

The assistance of Dale Rucker with the figures in the report, the thorough technical review and editing by Robert Neill, and the final editing by Linda Kennedy are also very much appreciated. 


\section{TABLE OF CONTENTS}

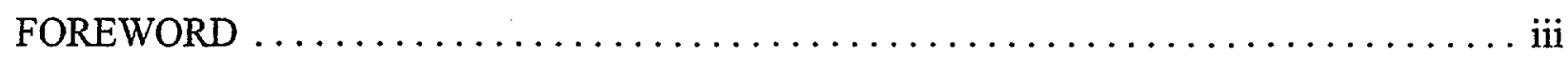

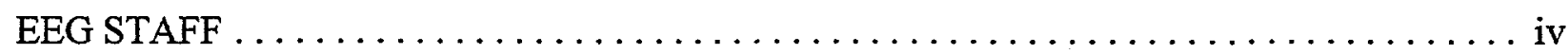

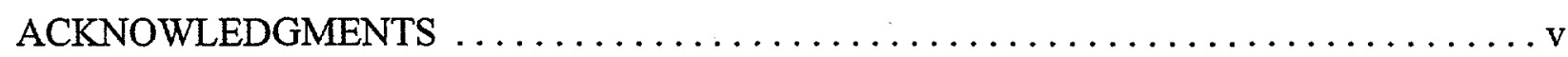

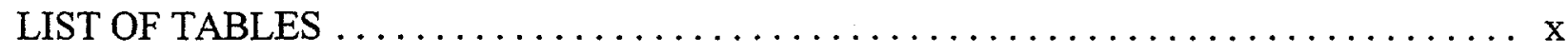

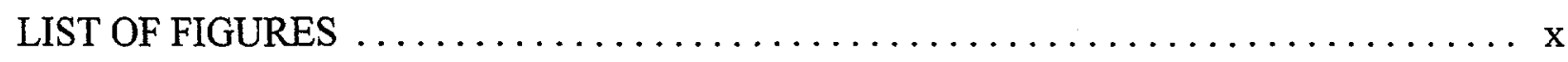

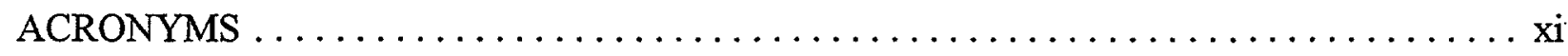

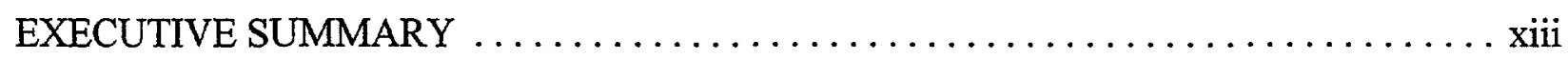

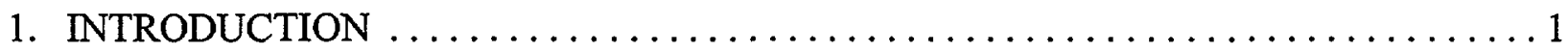

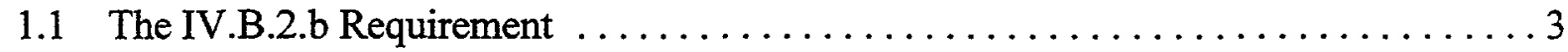

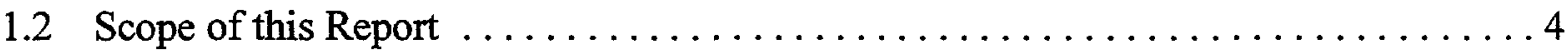

2. COMPARISON OF WAP TO WIPP PRE-PERMIT WASTE CHARACTERIZATION

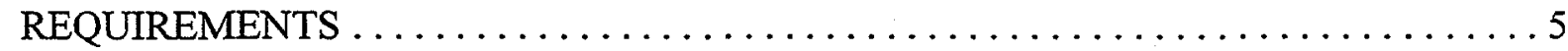

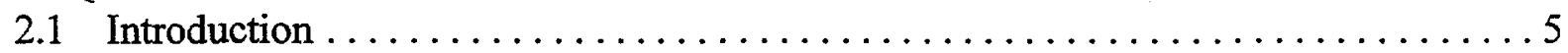

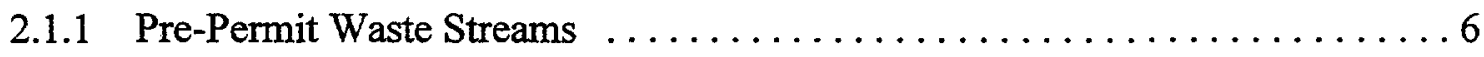

2.1.2 Data Quality Objectives (DQOs) and Quality Assurance

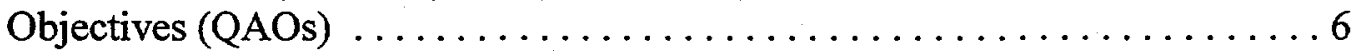

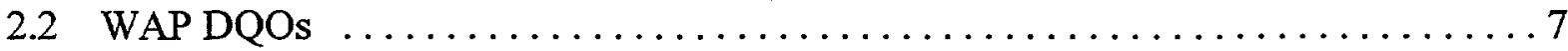

2.2.1 DQOs Related to Confirmation of Acceptable Knowledge $\ldots \ldots \ldots \ldots \ldots$. . 8

2.2.2 WAP Headspace Gas DQO . . . . . . . . . . . . . . . . . . 9

2.2.3 WAP Homogeneous Waste Sampling and Analysis DQOs ........... 9

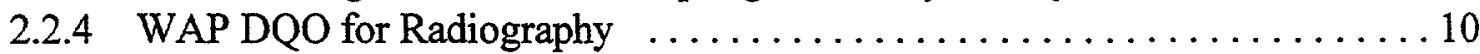

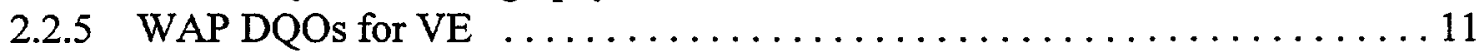

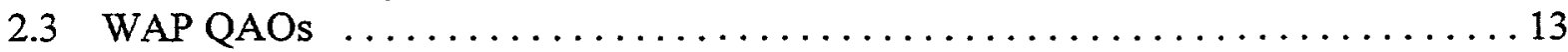

2.3.1 Headspace Gas QAOs ............................... 14

2.3.2 Deviations From QAPP Waste Characterization Requirements For

Headspace Gas ................................ 18

2.3.3 Homogeneous Solids and Soil/Gravel Sampling QAOs .............21

2.3.4 Deviations From QAPP Waste Characterization Sampling Requirements

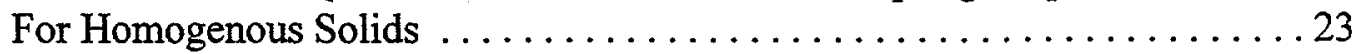

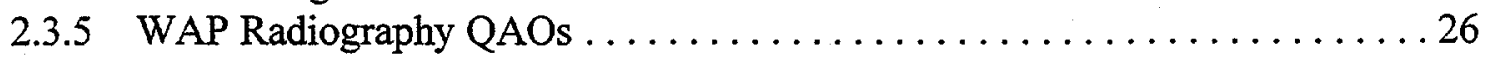

2.3.6 Deviation From QAPP Waste Characterization Sampling Requirements

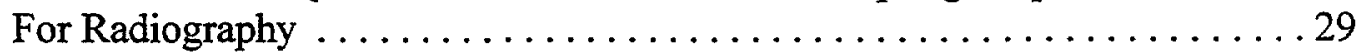


2.3.7 Total VOC Analysis QAOs (Section B3-6) . ................ 30

2.3.8 Total Semivolatile Organic Compound (SVOC) Analysis QAOS

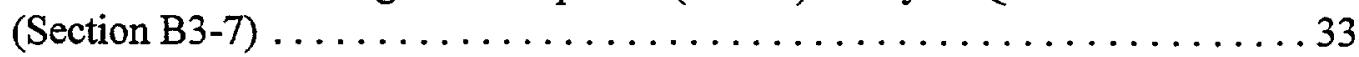

2.3.9 Total Metal Analysis QAOs (Section B3-8) $\ldots \ldots \ldots \ldots \ldots \ldots \ldots \ldots \ldots \ldots \ldots \ldots$

2.3 .10 Acceptable Knowledge ............................... 36

2.3.11 QAO Relating to Pre-Permit Waste Analysis Procedures Based on Deleted SW-846 Methods ............................. 38

2.3.12 QAOs Related to Data Usability Criteria .................. 40

2.3.13 SW-846 Modification and Representativeness QAOs ............. 41

2.3.14 Cancellation of Corrective Action Reports Related to the QAPP and Methods Manual ............................... 42

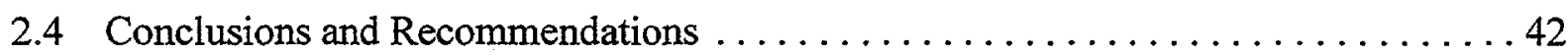

3. RISK ANALYSIS FROM ROUTINE OPERATIONS $\ldots \ldots \ldots \ldots \ldots \ldots \ldots \ldots \ldots$

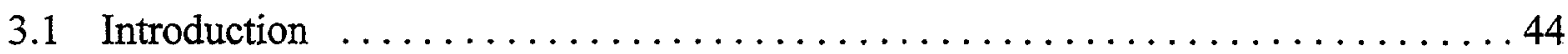

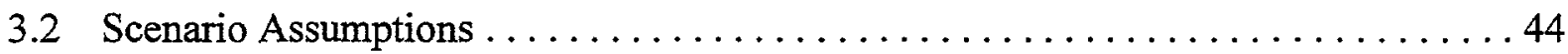

3.3 Determination of VOC Source Term $\ldots \ldots \ldots \ldots \ldots \ldots \ldots \ldots \ldots \ldots \ldots \ldots$

3.4 Risks to Surface Worker, Underground Worker, and Member of Public . . . . . . . 49

3.4.1 Carcinogenic Risks ............................... 50

3.4 .2 Non-Carcinogenic Risks . . . . . . . . . . . . . . . . . . . 51

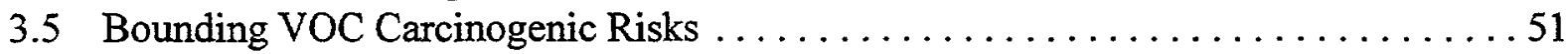

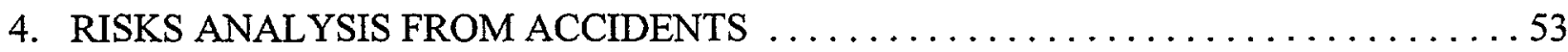

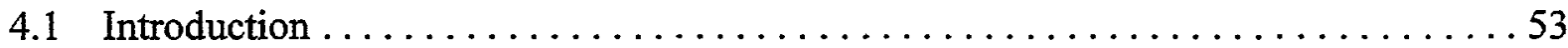

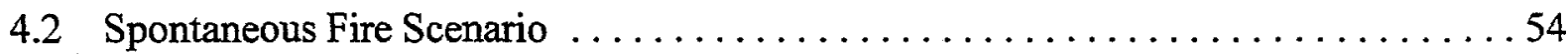

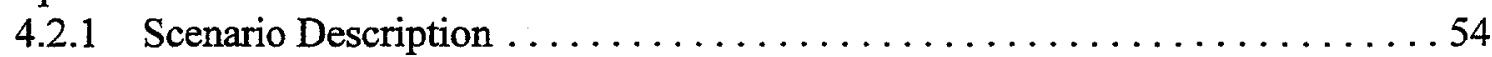

4.2 .2 VOC Release and Risk .................................. 54

4.2.3 Radionuclide Release and Risk ....................... 55

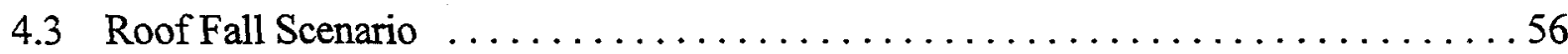

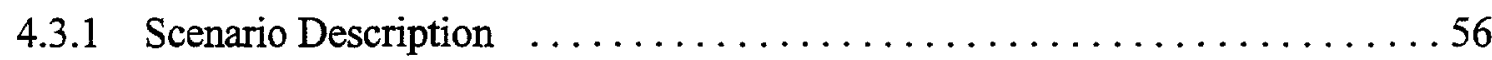

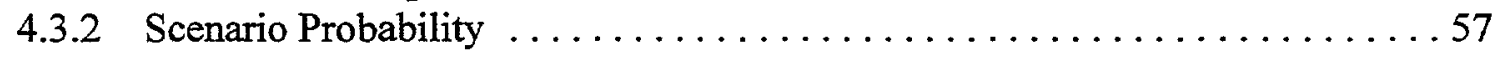

4.3.3 EEG Views on Roof Fall Probability in Panel 1. . . . . . . . . . . . 57

4.3.4 VOC Release and Risk .............................. 59

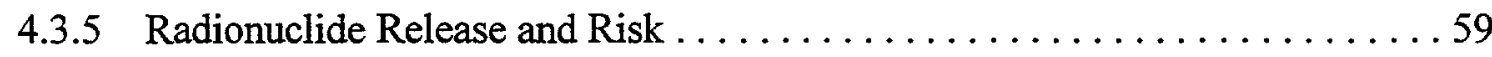

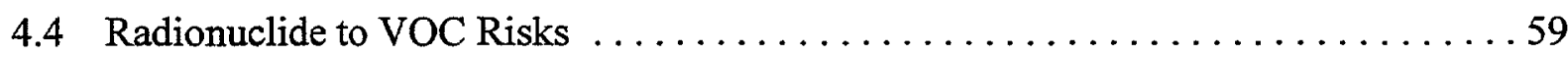

5. CONCLUSIONS \& RECOMMENDATIONS $\ldots \ldots \ldots \ldots \ldots \ldots \ldots \ldots \ldots \ldots \ldots \ldots \ldots \ldots$

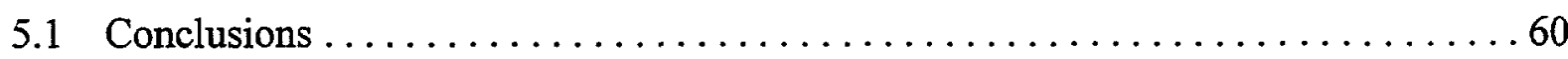

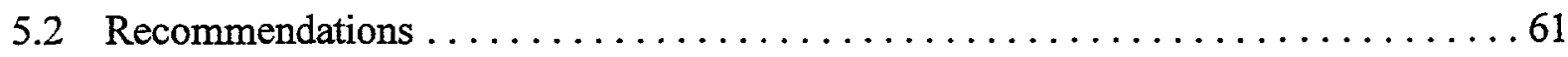

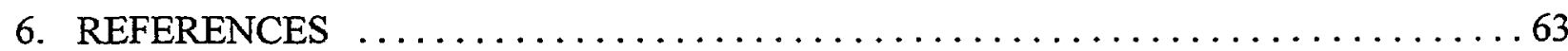

APPENDIX A. CALCULATION OF RISK ANALYSIS FOR ROUTINE OPERATIONS . . 67

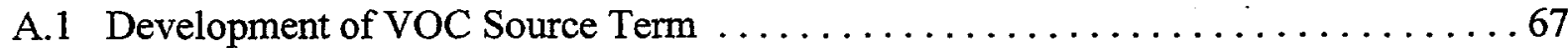

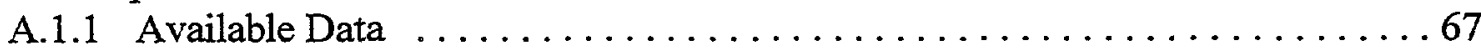




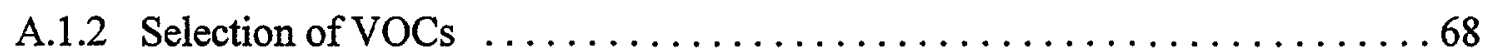

A.2 Exhaust Shaft and Environmental Concentrations $\ldots \ldots \ldots \ldots \ldots \ldots \ldots \ldots$

A.3 Risk to Surface Worker ............................... 71

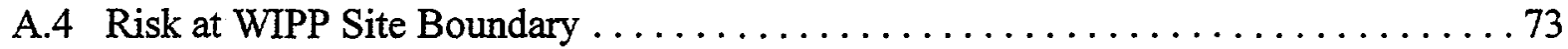

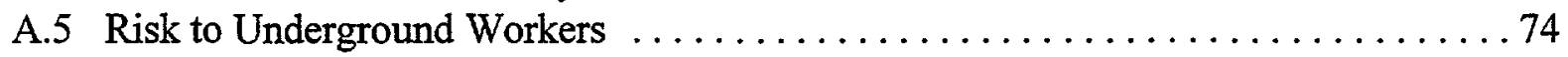

APPENDIX B. RISK ANALYSIS FROM ACCIDENTS $\ldots \ldots \ldots \ldots \ldots \ldots \ldots \ldots \ldots 77$

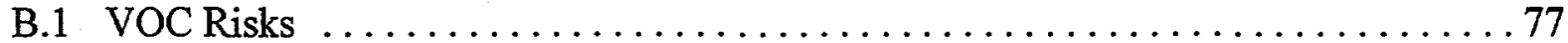

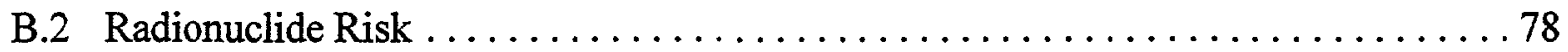

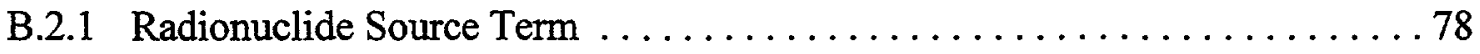

B.2.2 Radionuclide Cancer Risk . . . . . . . . . . . . . . . . . . . . . . . . 79

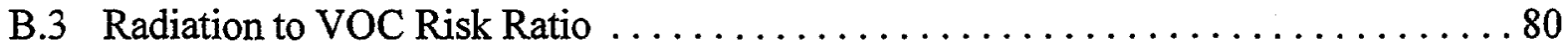

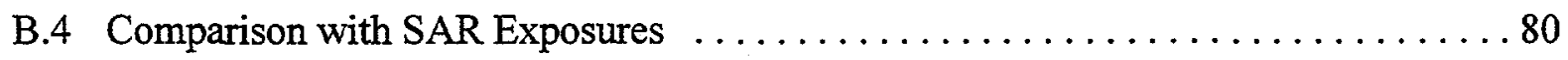

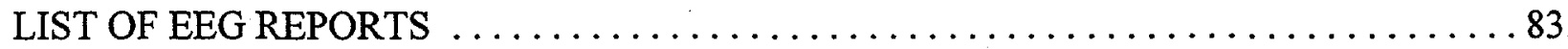




\section{LIST OF TABLES}

Table $3-1 . \quad$ VOCs Used in Risk Analysis $\ldots \ldots \ldots \ldots \ldots \ldots \ldots \ldots \ldots$

Table 3-2. Risks to Surface Worker, Underground Worker, and Member of Public . . . . . 50

Table 3-3. Carcinogenic Risks at MRL Values $\ldots \ldots \ldots \ldots \ldots \ldots \ldots \ldots \ldots \ldots \ldots$

Table 4-1. Radionuclide and VOC Carcinogenic Risks from Spontaneous Fire Scenario . . 56

Table A-1. VOC Concentrations in Pre-Permit Waste at WIPP . . . . . . . . . . . 69

Table A-2. VOC Concentrations in Exhaust Ventilation \& Environment From Pre-Permit

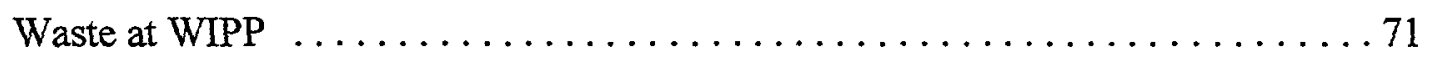

Table A-3. Annual Risks to Surface Worker from Carcinogens and Non-Carcinogens From Pre-Permit Wastes at WIPP . . . . . . . . . . . . . . 73

Table A-4. Annual Risks to Member of the Public from Carcinogens and Non-Carcinogens

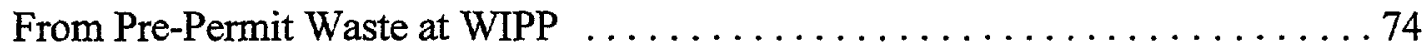

Table A-5. Annual Carcinogenic and Non-Carcinogenic Risks to an Underground Worker

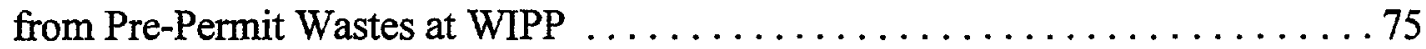

Table B-1. VOC Lifetime Fatal Cancer Risk to a Surface Worker from an Underground Fire Scenario at WIPP . . . . . . . . . . . . . . . .

\section{LIST OF FIGURES}

Figure $1-1$. WIPP Site Location in Southeastern New Mexico . . . . . . . . . . . . 2

Figure $3-1$. The WIPP Facility $\ldots \ldots \ldots \ldots \ldots \ldots \ldots \ldots \ldots \ldots \ldots \ldots \ldots \ldots \ldots \ldots \ldots$

Figure $3-2$. Waste Emplacement Process $\ldots \ldots \ldots \ldots \ldots \ldots \ldots \ldots \ldots \ldots \ldots \ldots$ 


\section{ACRONYMS}

$\mathrm{ADF} \quad$ Air Dispersion Factor

AK Acceptable Knowledge

amu Atomic Mass Unit

ASTM American Society for Testing and Materials

CAMs Continuous Air Monitors

CAO Carlsbad Area Office

CARs Corrective Action Reports

cfm Cubic feet per minute

CFRs Code of Federal Regulations

DCF Dose Conversion Factor

DOE U.S. Department of Energy

DQOs Data Quality Objectives

ECS Exhaust Shaft Concentration

EEG Environmental Evaluation Group

EPA U.S. Environmental Protection Agency

GC/ECD Gas Chromatography/Electron Capture Detection

GC/FID Gas Chromatography/Flame Ionization Detection

GC/MS Gas Chromatography/Mass Spectroscopy

HQ Hazard Quotient

HI Hazard Index

HSG Head Space Gas

HWA New Mexico Hazardous Waste Act

HWDU Hazardous Waste Disposal Unit

ICP-MS Inductively Coupled Plasma - Mass Spectroscopy

INEEL Idaho National Engineering and Environmental Laboratory

LANL Los Alamos National Laboratory

MDC Minimum Detectable Concentration

MIR Maximum Individual Receptor

MRI Method Reporting Limit 
NMAC New Mexico Administrative Codes

NMED New Mexico Environment Department

PDP Performance Demonstration Program

ppbv Parts per billion by volume

PRQL Program Required Quantitation Limit

QAOs Quality Assurance Objectives

QAPD Quality Assurance Program Document

QAPjP Quality Assurance Project Plan

QAPP Quality Assurance Program Plan

QC Quality Control

RCRA Resource Conservation and Recovery Act

RDF Risk to Dose Factor

RFETS Rocky Flats Environmental Technology Site

RPD Relative Percent Difference

RSD Relative Standard Deviation

RRF Average Response Factor

RTR Real-time Radiography

SAR Safety Analysis Report

SPCCs System Performance Check Compounds

SVOC Semi-volatile Organic Compound

SWB Standard waste box

TRU Transuranic

$\mathrm{UCL}_{90} \quad 90 \%$ Upper Confidence Level

UG Underground

URF Unit Risk Factor

VE Visual Examination

VOC Volatile Organic Compound

WAC Waste Acceptance Criteria

WAP Waste Analysis Plan

WID Waste Isolation Division

WIPP Waste Isolation Pilot Plant

WWIS WIPP Waste Information System 


\section{EXECUTIVE SUMMARY}

The U. S. Department of Energy's (DOE) Waste Isolation Pilot Plant (WIPP), located in southeastern New Mexico, has been constructed for the disposal of long-lived transuranic (TRU) waste. The New Mexico Environment Department (NMED) issued a Hazardous Waste Facility Permit (the Permit) to dispose of mixed waste at WIPP effective November 26, 1999. This Permit does not regulate the radioactivity in the waste. The DOE emplaced 44 shipments of nonmixed transuranic waste in Room 7 of Panel 1 before the Permit became effective. There also are a large number of waste containers at the generating sites that have been at least partially characterized prior to the effective date of the Permit.

Section IV.B.2.b of the NMED Permit contained language which appeared to prohibit emplacement of non-mixed wastes that were not characterized in accordance with the requirements of the Permit's Waste Analysis Plan (WAP). The justification for adding Section IV.B.2.b was that mixing WAP-certified wastes with pre-Permit wastes created unknown risks that should not be a part of Permit performance standards. Statements were made during Permit public hearings and in written testimony that the risks might be substantial, but there was no indication of the nature of these risks or their magnitude.

This report provides a technical evaluation, conclusions, and recommendations of the following Section IV.B.2.b issues:

1. A comparison of pertinent WAP requirements with pre-Permit waste characterization;

2. A risk analysis of the pre-Permit waste emplaced in Room 7. Expected and bounding risks from routine operations and possible accidents are evaluated. 


\section{Conclusions:}

1. The NMED approved WAP has made explicit many of the undocumented assumptions and implied good practices from the DOE's pre-Permit waste characterization program.

Although there are differences between the pre-Permit and WAP characterization programs, the pre-Permit program appears to substantially meet the technical requirements in the WAP.

2. Deviations granted by $D O E$ during pre-Permit waste characterization and premature closures of some corrective actions generated during independent audits may be the most significant differences from the Permit waste characterization requirements.

3. Estimated carcinogenic risks to an underground worker, a surface worker, and a member of the public due to routine operations from all the TRU wastes emplaced in Room 7 in 1999 are six to eight orders of magnitude less than risk levels allowed by the Permit. Noncarcinogenic risks are seven to ten orders of magnitude below allowed risks.

4. Even if VOC emissions are much higher than risk calculations estimate, the Confirmatory VOC Monitoring Plan in use at WIPP would detect concentrations that are three orders of magnitude below allowable Permit limits.

5. Risks to the surface worker and member of the public from low probability accidents are essentially all from radionuclide releases and are lower than the allowable Permit risks from routine VOC releases. The radionuclide risk to the underground worker is significant $\left(1.7 \times 10^{-3}\right.$ if the accident occurs). 


\section{Recommendations:}

Questionable data for the individual container lots of pre-Permit waste could be reviewed by NMED for conformance with the WAP requirements if necessary. This determination should consider all deviations and include input from the DOE.

The calculated non-accidental risks from the pre-Permit waste in Room 7 are too low to justify any remedial or other actions involving these wastes.

Radionuclide risks to underground workers from low probability spontaneous fire and roof fall accidents should be considered when setting restrictions on worker access to the south 1600 and east 300 drifts. 


\section{INTRODUCTION}

The Waste Isolation Pilot Plant (WIPP) Project is located in southeastern New Mexico (see Figure 1-1). WIPP has been constructed by the U.S. Department of Energy (DOE) to provide permanent disposal of long-lived transuranic (TRU) waste from the U. S. defense activities and programs.

Approximately $60 \%$ of the wastes to be disposed at WIPP is believed to be "mixed wastes"-wastes containing not only transuranic radionuclides, but also hazardous materials regulated under the federal Resource Conservation and Recovery Act (RCRA) (1976). Regulation of WIPP under RCRA has been delegated by the U. S. Environmental Protection Agency (EPA) to the New Mexico Environment Department (NMED), acting under the New Mexico Hazardous Waste Act (HWA) (1978). In October 1999 NMED granted a Hazardous Waste Facility Permit (the Permit) to WIPP that became effective on November 26, 1999 (NMED 1999b). This Permit regulates the management, storage, and disposal of only the hazardous waste components of the contact-handled transuranic mixed waste at WIPP. The Permit also requires that waste brought to the WIPP meet waste characterization requirements found in the Waste Analysis Plan (WAP), a series of appendices to the Permit (the " $B$ " attachments).

During the eight months prior to the promulgation of the Permit, the DOE disposed of 44 shipments of TRU (non-mixed) waste in Panel 1, Room 7, of the WIPP. This waste consisted of 101 standard waste boxes (SWBs) containing heat-source waste, 152 55-gallon drums of graphite waste, and 574 55-gallon drums of residues in pipe containers. These waste containers were characterized in a manner similar to, but not identical with, the Permit requirements contained in the WAP. The difference between the pre-Permit waste characterization program and the WAP requirements is of great importance due to Section IV.B.2.b of the Permit, as described in the next section. 


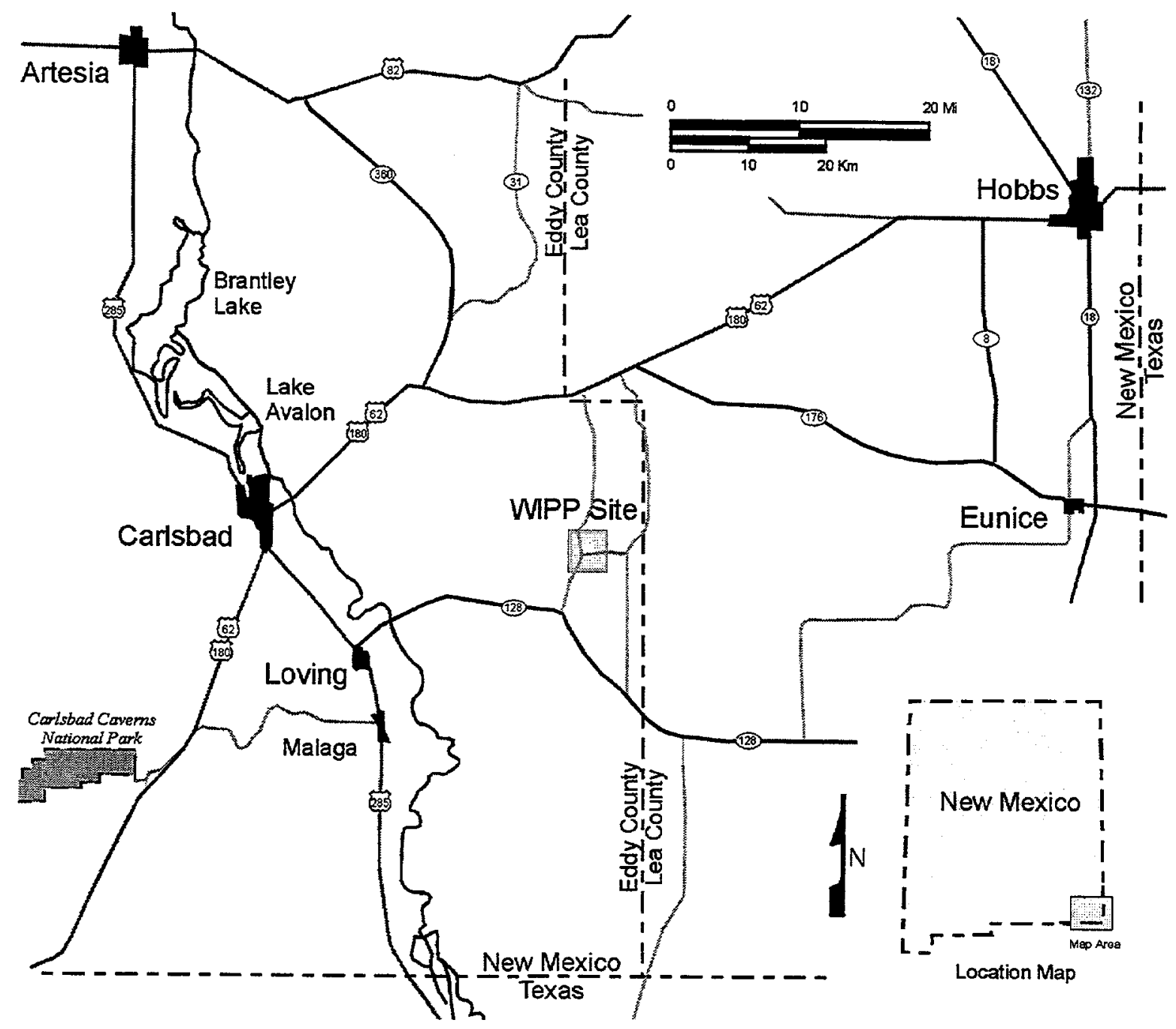

Figure 1-1. WIPP Site Location in Southeastern New Mexico 


\subsection{The IV.B.2.b Requirement}

Section IV.B.2.b of the Permit contains the following statement:

Specific prohibition -- After this permit becomes effective, (1) the Permittees shall not dispose non-mixed TRU waste in any underground HWDU unless such waste is characterized in accordance with the requirements of the WAP specified in permit Condition II. C.1 , and (2) the Permittees shall not dispose TRU mixed waste in any underground HWDU if the underground HWDU contains non-mixed TRU waste not characterized in accordance with the requirements of the WAP.

A WIPP underground hazardous waste disposal unit (HWDU) is a single waste disposal panel of seven rooms. There was considerable testimony about the pros and cons of Section IV.B.2.b requirements during public hearings and written testimony on the Permit. The justification for adding the requirement was that mixing WAP-certified wastes with pre-Permit characterized wastes created unknown risks that should not be a part of the RCRA performance standards of the repository. While some testimony indicated that these risks might be substantial, no one identified what these risks were or their possible magnitude.

The IV.B.2.b requirement poses two potential problems for the WIPP. A prohibition against adding of wastes certified under the WAP to the wastes already emplaced in Room 7 of Panel 1 could mean that Panel 1, which was designed to dispose of about 81,000 drum-equivalents of waste, would be limited to only the 1,400 drum-equivalents of pre-Permit waste already emplaced. Abandoning the rest of Panel 1 could reduce the design capacity of WIPP by about $10 \%$, and would delay emplacement of any more waste until mining of Panel 2 is completed (currently scheduled for October 1,2000). Such a delay could have significant impact, not only on operations at the WIPP, but at the DOE's TRU-waste generating sites as well.

A second problem from Section IV.B.2.b depends on whether pre-Permit characterization of wastes is determined to have been "characterized in accordance with the requirements of the WAP." In the pre-Permit waste characterization program, sites could begin characterizing waste for shipment to the WIPP as soon as the site Quality Assurance Project Plan (QAPjP) was 
deemed acceptable by the Carlsbad Area Office (CAO). Waste generator sites have been characterizing both mixed and non-mixed wastes for years under the pre-Permit waste certification requirements.

\subsection{Scope of this Report}

Both of the IV.B.2.b problems described in Section 1.1 are obviously controlled by the determination of whether pre-Permit wastes were "...characterized in accordance with the requirements of the WAP." This report presents a technical evaluation of considerations related to the IV.B.2.b issues described in Section 1.1. No evaluation was made of legal or regulatory aspects of Section IV.B.2.b.

Specifically this report:

1. Compares requirements of the WAP that are pertinent from a technical viewpoint with the WIPP pre-Permit waste characterization program;

2. Presents the results of a risk analysis of the currently emplaced wastes. Expected and bounding risks from routine operations and possible accidents are evaluated; and

3. Provides conclusions and recommendations. 


\section{COMPARISON OF WAP TO WIPP PRE-PERMIT WASTE CHARACTERIZATION REQUIREMENTS}

\subsection{Introduction}

This chapter focuses on the most pertinent requirements of the WAP from a technical viewpoint, and compares them to the requirements of the WIPP waste characterization program in operation to process pre-Permit wastes. Where possible, an evaluation of the impact of any differences is then expressed.

The DOE's TRU waste characterization program during the pre-Permit waste characterization period was governed principally by the Transuranic Waste Characterization Quality Assurance Program Plan (QAPP), Revision 0, with interim changes of February 1996 and November 15, 1996 (US DOE 1996d). Accordingly, the WAP requirements will be primarily compared to statements in US DOE 1996d. Other DOE documents that may be cited will be referenced in the text.

The CAO has granted variances from QAPP requirements during the pre-Permit period, labeling these variances at various times as equivalencies, clarifications, and guidances. A formal process for granting these variances has not been published, and EEG probably does not have documentation for all the changes granted. While these variances were granted to individual waste characterization sites, they could apparently be used for characterization at the other sites also. Since these variances also affect the comparison of the pre-Permit program to the WAP requirements, any variances that the EEG is aware of are also included in this analysis.

It is worth noting that there were effectively no changes in the WIPP waste characterization quality assurance program from the pre-Permit to the post-Permit period. While the QAPP was cancelled as a part of the move to comply with the Permit, the quality assurance program elements in it were moved to the CAO Quality Assurance Program Document (QAPD), 
Revision 3 (US DOE 1999f), which governs generator site waste characterization quality assurance programs.

\subsubsection{Pre-Permit Waste Streams}

The pre-Permit non-mixed wastes emplaced in the WIPP are from four different waste streams. Graphite mold waste streams from Rocky Flats Environmental Technology Site (RFETS) and Idaho National Engineering and Environmental Laboratory (INEEL) are divided into separate waste streams (RF 003.01 and IN W276.001). These two waste streams were apparently both created at RFETS from the same process. The other waste streams are $\mathrm{a}^{238} \mathrm{Pu}$ debris waste stream from Los Alamos National Laboratory (LANL) (TA-55-43.01) and the pyrochemical salt waste stream from RFETS (RF 005.001). Other waste streams accepted by the CAO that may have been characterized during the pre-Permit period include IN-W276.02, RF001.1, RF 002.01, and RF 004.01. Since submission of waste stream designations to the CAO during the prePermit period was not required before waste container characterization could begin, ${ }^{1}$ it is likely that containers from other waste streams were also characterized.

\subsubsection{Data Quality Objectives (DQOs) and Quality Assurance Objectives (QAOs)}

The WAP contains approximately 1500 individual statements that could be considered requirements, though a number of them are essentially duplicative. For example, there are multiple statements of the requirement that visual examination must be used to verify a statistically determined portion of radiographic results. The core requirements, however, are the data quality objectives (DQO)), which specify the waste characterization data necessary to meet the RCRA and HWA requirements.

${ }^{1}$ During the pre-Permit period, characterization of waste could begin on acceptance by the CAO of the generator site's waste characterization program documents. Characterization requirements were based on the summary category group (debris, homogeneous solids, or soil/gravel) assigned to each waste container. 
The WAP establishes specific data quality objectives in Section B-4a(1). In order to have confidence that the data reported meets the DQOs, various quality assurance objectives (QAOs) are also established in the WAP (Sections B3-2 through B3-9). If these DQOs and QAOs can be shown to have been met, then the sampling and analysis portions of the characterization could be considered complete (though reviews of these data may still be in question). As a subset of the complete requirements, the DQOs and QAOs would provide a sample of the kinds of problems the pre-Permit waste characterization program would have in demonstrating compliance with WAP requirements.

\subsection{WAP DQOs}

Section B-4a(1) of the draft WAP, entitled Data Quality Objectives, states that the following DQOs are established to satisfy the RCRA regulatory compliance requirements (pp. B-18 and B-19) $)^{2}$ :

- Headspace-Gas Sampling and Analysis

- To identify VOCs and quantify the concentrations of VOC constituents in the total waste inventory to ensure compliance with the environmental performance standards of 20 NMAC 4.1.500 (incorporating $40 \mathrm{CFR}, \S 264.601(\mathrm{~b})$ ), and to confirm hazardous waste identification by acceptable knowledge.

- Homogeneous Waste Sampling and Analysis

- To compare UCL $\mathrm{U}_{90}$ values for the mean measured contaminant concentrations in a waste stream with specified toxicity characteristic levels in 20 NMAC 4.1.200 (incorporating 40 CFR \$261), to determine if the waste is hazardous, and to confirm hazardous waste identification by acceptable knowledge.

- To report the average concentration of hazardous constituents in a waste stream, as specified in 20 NMAC 2.1.200 (incorporating 40 CFR

${ }^{2}$ VOCs are Volatile Organic Compounds; $\mathrm{UCL}_{90}$ is the $90 \%$ Upper Confidence Level (see Section B2-3 of the WAP for the formula); NMAC are the New Mexico Administrative Codes, the state analog of the Code of Federal Regulations (CFRs); PRQL is the Program Required Quantitation Limit. 
§261) Appendix VIII, with a 90 percent confidence interval, with all averages greater than PRQL considered a detection and subsequent assignment of the waste (if an adequate explanation for the constituent cannot be determined) as a hazardous waste, and to confirm hazardous waste identification by acceptable knowledge.

- Radiography

- To verify the TRU mixed waste streams by Waste Matrix Code for purposes of physical waste form identification and determination of sampling and analytical requirements, to identify prohibited items, and to confirm the waste stream delineation by acceptable knowledge.

- Visual Examination

- To verify the TRU mixed waste streams by Waste Matrix Code for purposes of physical waste form identification, determination of sampling and analytical requirements, and to identify prohibited items.

- To provide a process check on a sample basis by verifying the information determined by radiography, and to confirm the waste stream delineation by acceptable knowledge.

The wording of these WAP DQOs is significantly different than those found in the QAPP (Section 1.5, pp. 1-31 and 1-32), but for the most part, the WAP DQOs are reflected as requirements found elsewhere in the QAPP, as described below.

\subsubsection{DQOs Related to Confirmation of Acceptable Knowledge}

Several of the above DQOs establish a need to confirm acceptable knowledge information; in the QAPP, this requirement is found in several places, and a single statement in QAPP Section 4.2.2 covers the bulk of the WAP DQOs (p. 4-6):

Waste characterization (i.e., radiography, headspace gas sampling and analysis, and solidified waste sampling and analysis) will be used to confirm acceptable knowledge information. Figure 4-2 illustrates the process sites will use to confirm acceptable knowledge. 
The QAPP Figure 4.2 (p. 4-7) is a flow chart showing what comparisons are to be made, and the basis for either success or failure of the comparison. The terminology used above needs some interpretation: "Solidified waste sampling and analysis" as used in the QAPP is the equivalent to the WAP's "homogeneous waste sampling and analysis"; and visual examination (VE) is considered in the QAPP as an adjunct to radiography. Section 4.2.2.1 of the QAPP more clearly establishes the requirement for VE and radiography to confirm acceptable knowledge (p. 4-6):

Radiography or visual examination must be used to confirm the matrix parameter category and waste material parameters identified using acceptable knowledge.

Other DQO requirements need to be addressed individually. Each DQO listed in Section 2.2 above is addressed in the following sections.

\subsubsection{WAP Headspace Gas DQO}

The WAP headspace gas DQO is for identification and quantification of VOC constituents in the waste to ensure compliance with the environmental performance standards of 20 NMAC 4.1.500, “incorporating 40 CFR, §264.601(b)." Section 40 CFR 264.601(b) is a list of considerations that must be taken into account concerning migration of wastes from a HWDU. The 40 CFR 264.601(b) reference in the WAP may be an error, as subparagraph (b) is more applicable to solid and liquid wastes ("migration of waste constituents in surface water, or wetlands or on the soil") rather than VOCs. Subparagraph (c), which covers "migration of waste constituents in the air" would seem to be the more pertinent citation. In any case, meeting this DQO is clearly a function of meeting the QAOs for headspace gas, as described in Section 2.3 below.

\subsubsection{WAP Homogeneous Waste Sampling and Analysis DQOs}

The DQO for comparing $\mathrm{UCL}_{90}$ values for the mean concentrations in each homogeneous waste stream with the 40 CFR 261 toxicity values is also a DQO in the QAPP (Section 1.5, p. 1-32). 
The DQO for reporting average waste stream concentrations of the 40 CFR 261 Appendix VIII hazardous wastes with a $90 \%$ confidence for all averages greater than the PRQL is briefly described in the QAPP in Section 1.4 (pp. 1-29 and 1-30):

TRU waste classified as homogenous solids and soil/gravel must be statistically sampled and analyzed for the constituents listed in Table 1-3 as VOCs, SVOCs, and metals. The mean concentration of hazardous constituents (40 CFR Part 261, Appendix VIII) must also be calculated by waste stream and then reported to CAO with an upper 90-percent confidence limit $\left(\mathrm{UCL}_{90}\right)$ as described in Section 3.3 of this QAPP.

Section 4.2.2.2 of the QAPP adds the requirement that averages greater than the PRQL must be re-evaluated. However, this requirement applies only to spent solvents, rather than all of the Appendix VIII listing (p. 4-8):

Sites must confirm the assignment of spent solvent EPA hazardous waste numbers ( 40 CFR §261.31) by evaluating the mean concentrations of each VOC detected in container headspace gas and/or solidified waste matrix. The $\mathrm{UCL}_{90}$ for the mean constituent concentration must be compared to the PRQL for the constituent.

Appendix VIII contains hazardous materials that are not spent solvents but will still be in WIPP wastes. For example, lead, which will likely be the most prevalent hazardous material disposed of in the WIPP repository, is listed in Appendix VIII. The WAP DQO for reporting of Appendix VIII wastes in quantities greater than the PRQL does not appear to be completely met in a clear manner for all of the DOE's pre-Permit waste characterization processes.

\subsubsection{WAP DQO for Radiography}

The WAP DQO is essentially identical to the QAPP DQO in that radiography is to verify the waste matrix code assigned to each waste stream (Section 1.4, p. 1-32):

To verify the TRU waste streams by matrix parameter category, as described in the BIR, for purposes of physical waste form identification and determination of sampling and analytical requirements. 
"Waste matrix code" is not defined in the Permit, though it may be a term defined in the RCRA and HWA regulations referenced by Section I.D. In the DOE documentation, "waste matrix code" and "matrix parameter category" are identical terms, meaning the five-digit alphanumeric codes used to classify wastes for treatment as found in the DOE Waste Treatability Group Guidance (Kirkpatrick 1995). That these are identical terms is made explicit in Section 1.4 of the QAPP (p. 1-18 and 1-19).

The WAP DQO also states that radiography is to identify prohibited items, apparently meaning the items listed in Section B-1c, "Waste Prohibited at the WIPP Facility", that are amenable to radiographic identification (liquids, explosives, compressed gases, and perhaps non-radionuclide pyrophoric materials). The QAPP does not include mention of prohibited items as a DQO, though it does specify that radiography operators be trained to find these items (in language which is nearly identical to that used in the WAP). The requirement for identification of prohibited items is also not clearly spelled out in the QAPP, but Section 4.2.1 does contain the following statement (p. 4-3):

Sites must ensure radiography and visual examination procedures include a list of nonconforming items that the operator must verify are not present in each container of waste (i.e., corrosives, ignitables, reactives, incompatible waste).

\subsubsection{WAP DQOs for VE}

The QAPP contains no explicit DQOs for visual examination, but the WAP visual examination DQOs are included as requirements in the QAPP in other ways. The WAP DQOs require that VE verify waste matrix codes, identify prohibited items, verify radiography information, and confirm waste stream delineation by acceptable knowledge.

The QAPP considers use of VE in two ways: as verification of radiography findings (which in turn verifies acceptable knowledge) for retrievably stored wastes, and as confirming acceptable 
knowledge for newly generated wastes or repackaged wastes. For verification of waste matrix codes (matrix parameter categories) Section 3.2 of the QAPP states (p. 3-6):

...radiography and visual examination are complementary techniques yielding similar data for determining the matrix parameter category and waste material parameter weights of waste present in a waste container. Therefore, visual examination results shall be used to verify the matrix parameter category and waste material parameter weights determined by radiography as described in Section 10.0.

The QAPP requirement for use of both VE and radiography to identify prohibited items is in Section 4.2.1 (see radiography discussion above), and individuals performing VE must also be trained to recognize prohibited items. The QAPP Section 4.2.1 clearly requires verification of acceptable knowledge for newly generated wastes (p. 4-5):

For newly generated waste streams, sites must describe how acceptable knowledge information is confirmed using visual examination prior to or during waste packaging.

While the QAPP does not specifically state that VE will be used to verify waste stream delineation for retrievably stored wastes, it is an implicit assumption in the QAPP that this activity will be performed. For example, Section 4.2.2.1 states the following (which also addresses waste matrix codes; p. 4-5):

For all waste streams, sites must describe how acceptable knowledge information is re-evaluated if radiography or visual examination results in the reassignment of a different matrix parameter category [e.g., Plastic/Rubber (S5310) versus Paper/Cloth (S5330)]. For all waste streams, sites must describe how waste is reassigned to a different waste stream and appropriate EPA hazardous waste numbers assigned.

Verification of radiography by VE is required in the QAPP in Section 5.0 (p. 5-4):

Retrievably stored waste containers from waste streams in all matrix parameter categories (S3000, S4000, and S5000 summary categories) must be selected for 
visual examination to confirm the results of radiography following the statistical approach specified in Section 5.4.1.

The statistical approach described in the QAPP and the WAP are the same with one significant difference. The QAPP invokes the use of statistics over the entire drum population, whereas the WAP requires that it be applied to each waste stream. This WAP requirement could easily result in a ten-fold increase in the number of drums that must be examined by each generator site in a year. The WAP also requires an initial statistical selection of drums based on an $11 \%$ miscertification rate whereas the QAPP requires an initial selection based on a $2 \%$ miscertification rate. The WAP miscertification rate would also increase the number of containers that should undergo visual examination. This potential increase does not significantly affect the pre-Permit wastes in the repository, since nearly all underwent visual examination during repackaging, but other wastes characterized by generator sites in the pre-Permit period may be significantly affected.

Some of the requirements quoted above are found multiple times within the QAPP. Except for the frequency of visual examination to verify radiography, the pre-Permit waste characterization program appears to meet the WAP DQOs for visual examination.

\subsection{WAP QAOs}

The DQOs are reached through meeting QAOs for each of the areas described. The following sections compare the QAOs in the WAP to the WIPP pre-Permit program requirements. The WAP QAOs are not always reflected in the QAPP as QAOs, but can still usually be found as requirements within the document. Headspace gas QAOs will be addressed first, since these are a primary consideration in concerns related to the Room 7 risk analysis. 


\subsubsection{Headspace Gas QAOs}

For VOC analysis the WAP clearly establishes the link between DQOs and QAOs. Section B35, Gas Volatile Organic Compound Analysis, in the portion labeled Quality Assurance Objectives, states:

The development of data quality objectives (DQO) specifically for this program has resulted in the QAOs listed in Table B3-2. The specified QAOs represent the required quality of data necessary to draw valid conclusions regarding program objectives. WAP-required limits, such as the program required quantitation limits (PRQL) associated with VOC analysis, are specified to ensure that the analytical data collected satisfy the requirements of all data users.

The WAP Table B3-2, Gas Volatile Organic Compounds Target Analyte List and Quality Assurance Objectives, is identical in all technical respects to QAPP Table 12-1, for the GC/MS (gas chromatography followed by mass spectroscopy) or GC/FID (gas chromatography followed by flame ionization detection) methods used for all pre-Permit characterization activities. ${ }^{3}$ For these QAOs, the pre-Permit waste characterization program requirements are identical to those specified in the WAP.

Table B3-2 covers headspace gas analysis only. There are also QAOs for headspace gas sampling (also listed in Section B3-2). The first of these states (p. B3-6):

Headspace-gas sampling will occur from the headspace within each drum of transuranic (TRU) mixed waste.

${ }^{3}$ The Fourier Infrared Transform Spectroscopy (FTIRS) MDL column in the WAP Table B3-2 does not appear in Table 12-1 of the QAPP, though the same MDL values for all but formaldehyde and hydrazine appear in Table 1 of the QAPP's February 1996 Interim Change (p. 4). FTIRS analysis, however, was not approved for use in TRU waste characterization at any DOE site during the pre-Permit period, and none of headspace gas results for pre-Permit activities were performed by FTIRS. The QAPP Table 12-1 also includes three additional analytes (to address a transportation requirement) not listed in the WAP Table B3-2. 
This WAP statement is unduly limiting since standard waste boxes sent to WIPP also need headspace gas sampling. The use of the term "drum" rather than "waste container" was probably an unintended error. In the QAPP, the requirement is more inclusive (Section 4.2.2.2, p. 4-8):

Headspace gas sampling and analysis must be conducted on all TRU waste to be sent to the WIPP facility.

There have been deviations from this requirement for pre-Permit wastes, and there is a qualification in the WAP QAOs that may arguably allow these deviations. See Section 2.3.2 for a fuller discussion of the deviations.

A second QAO for headspace gas is that the precision and accuracy of the drum headspace gas sampling operations must be assessed by analyzing field quality control (QC) head space gas sample to include equipment blanks, field reference standards, field blanks, and field duplicates. The identical wording from Section B3-2 in the WAP is in Section 7.1 of the QAPP (p. 7-3).

QAOs for precision, accuracy, completeness, comparability, and representativeness of the headspace gas samples are also found in Section B3-2. Each of these QAOs consist of several statements containing individual requirements, and all of the requirements in these statements are addressed by various portions of the QAPP (though not necessarily as QAOs) except for the following items.

1. The WAP precision QAO for headspace gas requires sequential collection of field duplicates from manifold sampling operations. The QAPP does not specify sequential collection of field duplicates from manifold sampling--the requirement is for field duplicates to be collected simultaneously, whether for manifold or direct canister sampling.

The WAP requirement for manifold collection would establish a slightly more rigorous check of sampling than is required by the QAPP, but only if cleaning of the manifold or some other change to the system was specified between collection of the-sequential samples. However, the logic for requiring sequential sampling from manifolds instead of 
simultaneous sampling is not clear. Other sections of the WAP indicate that simultaneous collection is sufficient. For example, Section B1-1a(1), Manifold Headspace Gas Sampling (p. B1-3) states:

If using canister-based sampling methods, a sufficient number of ports shall be available to allow simultaneous collection of headspace-gas samples and duplicates for VOC analyses.

The "canister-based sampling methods" are not to be confused with "direct canister sampling"; using a manifold, samples can either be stored in canisters (canister-based sampling method), or directed to an on-line analytical system for immediate processing. Direct canister headspace gas sampling does not use a manifold.

2. The WAP completeness $\mathrm{QAO}$ for headspace gas sampling requires that sampling completeness is to be calculated for each waste stream, and must be $90 \%$ or greater. While the requirement for $90 \%$ sampling completeness is in the QAPP, there is no specification for calculation by waste stream for headspace gases (or any of the other waste characterization parameters). The QAPP does, however, require that (Section 3.3.1, pp. 3-9 and 3-10):

...the site project manager will ensure that all data generated meet the DQOs provided in Section 1.5 of this QAPP. To do so, the site project manager must assess whether data of sufficient type, quality, and quantity have been collected...

For each waste stream characterized the site program manager must determine if sufficient data have been collected to determine the following Program-required waste parameters: ...Average concentration of hydrogen, methane, and each VOC in the headspace gas of waste containers in the waste stream.

Section 7.1 of the QAPP (p. 7-3) also requires the site project QA officer to evaluate the importance of any lost or contaminated headspace gas samples, and initiate corrective action if appropriate. While these statements are not the equivalent of the WAP 
requirement, they do indicate that the sufficiency of headspace gas data for each of the waste streams that have already been placed into the WIPP has been specifically evaluated and deemed acceptable, and that any samples not used have also been assessed for their importance to the quality of data.

3. The WAP comparability QAO for headspace gas sampling requires laboratories analyzing WIPP samples to successfully participate in the CAO's Performance Demonstration Program (PDP; blind test samples are processed by the labs at least annually to help assess lab compliance with QAOs). ${ }^{4}$ The QAPP only requires that laboratories participate in the PDPs (Section 2.3, p. 2-7), and comply with the PDP Plans. ${ }^{5}$

The original Headspace Gas PDP Plan (US DOE 1995a) does require any laboratory that fails to meet the PDP criteria for accuracy or precision to cease analytical operations for WIPP samples (see Rev. 0 paragraph 6.2.5.6.2, p. 25), which would seem to clearly meet the WAP requirement. Revision 1 (US DOE 1999b) no longer requires laboratories to cease analysis of WIPP samples until a successful PDP cycle has been obtained; under Revision 1 laboratories may "choose to proceed at risk," though any data obtained "may be found unacceptable to WIPP" (Section 5.2.5 p. 26). The WAP, however, was developed using Revision 0 , and successful participation in the PDP would seem to mean meeting the PDP criteria. After April 14, 1999--when Revision 1 was promulgated-- the WIPP waste characterization program does not meet this WAP QAO for headspace gas. It may be, however, that DOE-certified generator sites (LANL, INEEL, and RFETS) have consistently met the PDP criteria in the relatively short intervening period.

4. The WAP comparability $\mathrm{QAO}$ for headspace gas sampling also requires the generator site to take corrective action if uniform procedures, equipment, or operations are not followed,

${ }^{4}$ The inclusion of the PDP requirement in a QAO for headspace sampling seems out of place--the Headspace PDP does not include testing of sampling processes, only testing of laboratory analytical capability.

${ }^{5}$ The requirement to comply with the PDP plans are found in the November 1996 Interim Change to the QAPP, Table AC-1 (US DOE 1996d). 
unless the deviations have been justified and approved. The QAPP does not address this requirement in these terms, but Section 2.1 (p. 2-1) states:

Corrective action shall be taken if any condition, or significant condition, adverse to quality is detected during an audit or assessment. The cause of any adverse condition, identified by any means, that affects compliance with the $\mathrm{QA} / \mathrm{QC}$ requirements specified in this QAPP shall be promptly determined and action taken to preclude its recurrence. The identification, cause, and corrective action(s) for conditions not complying with the quality requirements of the Program must be documented and reported to appropriate levels of management as indicated throughout this section.

Section 2.1.2.1 of the QAPP (p. 2-3) covers nonconformances, defined as uncontrolled and unapproved deviations from an approved plan (including the QAPP), procedure, or expected result. Nonconformances can be identified and reported by anyone performing WIPP project activities, and are to be tracked to completion by the site project QA officer. Completion of corrective action for nonconformances must also be verified by the site project QA officer.

There have been some deviations from the requirements in the QAPP for the wastes that are now in the WIPP repository. However, as specified in this QAO, these have been justified and approved, as is indicated in the next section.

\subsubsection{Deviations From QAPP Waste Characterization Requirements For Headspace Gas}

Two major deviations from headspace gas requirements in the QAPP for pre-Permit waste characterization are listed in the following comments.

1. Headspace gas samples from the LANL TA-55-43.01 waste stream were taken prior to repackaging of these wastes, when the waste container was a 55-gallon drum; the contents of each of these drums was later repackaged into one or more standard waste boxes in order to meet hydrogen gas generation requirements (a transportation requirement, not a RCRA 
one). Each SWB received waste from only one drum. Standard waste boxes provide a much greater headspace volume than do drums, therefore, headspace gas concentrations that met requirements while in drums would assuredly meet the same requirements in SWBs.

Since the QAPP did not specify when samples are to be taken, LANL requested guidance on the issue from the CAO. The CAO responded with a July 8, 1998, letter to LANL (Hunter 1998b) that states:

...if retrievably stored waste is repackaged after headspace gas sampling, then it is not necessary to resample the waste.

The organization responsible for enforcing the WIPP RCRA permit, the New Mexico Environment Department, was extensively involved in reviewing waste characterization for this waste stream, and eventually agreed with the DOE that the waste stream contained no reportable RCRA hazardous constituents. Accordingly, the lack of a headspace gas sample from the final waste containers (the SWBs) may meet the WAP headspace gas comparability QAO for justification and approval of deviation from the WAP headspace gas process.

It should be noted that the WAP QAOs for headspace gas do not require sampling of SWBs; the QAO only specifies drums (the EEG has informed the NMED about this apparent terminology oversight in the WAP).

2. No headspace gas samples were collected for the RFETS waste stream RF 005.01 since it consists of solid salt waste which is heated to a liquid 800 degrees Celsius and stirred for approximately two hours in the presence of an oxidant. The process should remove any RCRA headspace gas-generating materials or volatile organic compounds that might be present in the salt.

RFETS requested an exemption from the CAO for headspace gas sampling of these salt wastes, and a February 12, 1998, letter from the CAO's Office of National TRU Waste 
Operations (Hunter 1998a) granted the exemption, noting that the post-heating packaging would prevent re-introduction of headspace gas constituents into the waste. There appears to be no technical reason for performing headspace gas sampling of the post-heating wastes from this waste stream.

3. An October 9, 1998, CAO letter (Hunter 1998g) grants a RFETS request to deviate from a waste container temperature equilibrium requirement. The requirement is stated in the QAPP as follows (Section 6.4.1):

Waste containers and their contents must be allowed to equilibrate to the temperature of the sampling area. The equilibrium period must be, at a minimum, 72 hours prior to sampling.

The letter notes that the requirement is only to allow the waste container and its contents to equilibrate to the temperature of the sampling area, not reside at the sampling area for the 72 hour period, and that even if containers were left at the freezing point for a short period of time they could still be brought to $64.4^{\circ} \mathrm{F}\left(18^{\circ} \mathrm{C}\right)$ in less than 72 hours.

The WAP requirement (Section B1-1a) specifies equilibration for 72 hours at $18^{\circ} \mathrm{C}$ or higher. This would ensure that headspace gases would reach equilibrium conditions at that temperature. The CAO's October 9, 1998, interpretation does not meet this intent.

4. A January 12, 1999, CAO letter to Mobile Characterization Services (Brown 1999a) allows use of a heated syringe for collection of duplicate samples, stating that because the syringe method has been shown to meet program quality assurance objectives and the syringe will collect a sufficient volume, the duplicate would be equivalent to the $\mathrm{SUMMA}^{\oplus}$ canister collection system required by the QAPP. Transportation and storage requirements for the syringe method were not discussed in the letter.

The WAP contains no provisions for using syringes to obtain duplicate headspace gas samples. Any duplicates obtained by this method would be suspect. 


\subsubsection{Homogeneous Solids and Soil/Gravel Sampling QAOs}

The WAP homogenous solids and soil/gravel sampling QAOs are, like the headspace gas QAOs, usually found as identical requirements within the QAPP. Differences between the WAP and QAPP requirements are as follows:

1. The WAP Section B3-3 (p. B3-9) states that "25 to 30 pairs of co-located cores or samples" are to be used to establish control charts for the relative percent difference (RPD) between field duplicate samples. The QAPP requires "at least 30" pairs of co-located samples. The QAPP requirement is the more conservative--the more samples used to establish the control limits the more likely the controls will accurately reflect the mean and variance of the population.

2. The WAP Section B3-3 (p. B3-9) requires that RPD control charts establish limits at three standard deviations. The QAPP states (Section 8.3, p. 8-8a):

The limits may be as much as three standard deviations from the mean.

That is, the control limits may be less than three standard deviations, but not more; again, the QAPP is more conservative than the WAP requirement.

3. The WAP Section B3-3 QAOs for accuracy (p. B3-9) requires that:

Sampling accuracy as a function of sampling cross-contamination will be measured.

The QAPP contains no comparable statement. However, the WAP does not indicate how measuring sampling accuracy as a function of sampling cross-contamination might be done--there is no other mention of it in the entire permit. The utility of performing this action seems technically dubious unless a creditable methodology is available, and criteria for the results are specified. 
4. The WAP Section B3-3 QAOs for accuracy (p. 3-9) requires that "corrective action must be taken" if equipment blanks from a cleaning batch sample analysis shows hazardous constituents that exceed three times the minimum detectable levels; the QAPP specifies that the corrective action (reclean the entire cleaning batch and take a new sample, pp 8-8c and 8-9). The WAP permits other corrective action, including disposal of the cleaning batch.

5. The WAP Section B3-3 QAOs requires laboratories analyzing WIPP samples to successfully participate in the CAO's Performance Demonstration Program. As was true with the headspace gas PDP, the QAPP only requires that laboratories participate in the PDPs (Section 2.3, p. 2-7) and comply with the PDP Plans.

As with the headspace gas PDP Plan, the original PDP Plan for solidified wastes (US DOE 1995b) required analytical labs to cease operations when the PDP criteria are not met.

Revision 1 (US DOE 1996a), submitted to the administrative record for the Permit, kept the requirement. However, Revision 2 (US DOE 1999c), allows the laboratories to "choose to proceed at risk," though any data obtained "may be found unacceptable to WIPP." Since successful participation in the PDP would seem to mean meeting the PDP criteria, the WIPP waste characterization program does not meet this WAP QAO after the April 14, 1999 issuance of Revision 2.

However, only two waste generating sites have been certified to perform solid sampling by the DOE. These two sites may have continued to meet the PDP criteria; one of the sites (LANL) may not have characterized solids since the change in the PDP Plan.

6. The WAP Section B3-3 QAOs for representativeness (p. B3-10) require that in coring, the entire depth of the waste "minus a site defined approved safety factor" is to be taken; the QAPP does not explicitly make an allowance for the safety factor.

7. The WAP Section B3-3 QAOs for representativeness (p. 3-10) require that, in taking a core sample, if an insufficient ( $<50 \%$ of the total length possible) portion of the initial core is 
not obtained, that a second core is to be taken; "the core with the best core recovery shall be used for the sample." The QAPP specifies that in this situation the second core is always to be used regardless of the recovery length (Section 8.1, p. 8-3).

The WAP requirement is based on one aspect of achieving a representative sample (taking samples from a more representative core length), the QAPP requirement perhaps based on another-- the length of time before samples are removed from the core. The second core, even if shorter, would be more likely to retain VOCs than the first core, as the first core could be losing VOCs by diffusion while the second core is taken.

\subsubsection{Deviations From QAPP Waste Characterization Sampling Requirements For Homogenous Solids}

There are several deviations from the QAPP waste sampling and preservation requirements for homogeneous wastes.

1. Pre-Permit samples from the RFETS salt waste stream RF 005, a homogeneous solid at normal temperatures, have not all been obtained by coring as is specified in the QAPP. These wastes were heated to a liquid state as a part of their processing, stirred for approximately two hours, then a liquid sample was dipped from the mix. RFETS requested allowance for this practice from the CAO, and received it (Hunter 1998a, p. 2). The CAO approval noted that an SW-846 (US EPA 1996) process allowed such sampling, as the stirring addressed the vertical inhomogeneity issue that was a caveat in the SW-846 process.

The WAP contains no provisions that would allow this process, but there seems to be no technical reason for considering such samples to be less valid than those obtained by the

6 "SW-846" is the EPA's Test Methods for Evaluating Solid Waste, Physical/Chemical Methods, a compendium of methods for sampling and analysis of RCRA wastes. The CAO letter cites Section 9.2.3, Sample Plan Implementation Containers. 
allowed coring methodology. The CAO approval letter states that the RFETS process will yield a more representative sample, which seems reasonable, although the CAO cited no studies to support the conclusion.

2. A July 14, 1998, CAO letter (Hunter 1998c) grants RFETS exemption from preserving samples of waste stream RF 005 salt waste by storing them at $4^{\circ} \mathrm{C}$. The requirement is to prevent volatilization of mercury and chromium from the sample; the letter points out that the mercury would be removed from the waste during the two-hour $800^{\circ} \mathrm{C}$ heating process, and the SW-846 methods for total chromium analysis (as opposed to hexavalent chromium analysis) do not require cooling of the sample. The WAP requirements for chromium seem to have been effectively met, as SW-846 procedures are specified for metals analysis.

A September 29, 1998, CAO letter (Hunter 1998f) notes that, despite the heating process, samples did show the presence of trace concentrations of mercury. The letter states that:

...the Carlsbad Area Office (CAO) agrees with your determination that the presence of mercury in two of over 200 samples, and at trace concentrations, does not invalidate the $\mathrm{CAO}$ approval to eliminate the need to cool salt residue samples to 4 degrees. The rationale provided, along with the letters from two outside technical experts, sufficiently documents the validity of the preservation protocol used for these types of samples.

While it seems unlikely that cooling the samples would have resulted in detection of higher concentrations of mercury, the deviation from the QAPP sampling requirements makes that determination only a highly logical conjecture rather than a technically justified conclusion. This process does not meet WAP requirements, but again, the technical consequence seems minor.

3. A February 25, 1999, CAO letter (Brown 1999b) notes that duplicate samples from liquified RF 005 waste stream are not necessary, specifying that relative percent differences were to be calculated from sub-samples of single samples taken. The homogeneity of the liquified salt and the quality of the sampling process itself would have been confirmed by a 
complete duplication of the process, and this change does not meet WAP requirements. However, individual small containers of liquid waste are constantly stirred for an hour before the sample is taken, and the composition of sub-samples would likely have the same variance as multiple samples; the granting of this change would not seem to significantly affect analytical results.

4. An August 21, 1998, CAO letter (Hunter 1998d) grants RFETS exemption from coring of homogeneous residue salts (a different group of salt residues than the RF 005 waste stream discussed above). The alternate methodology approved includes size reduction, use of a mixing and sampling process based on ASTM C702-93, and use of SW-846 approved containers and procedures for storing and handling the resulting sample.

The letter states that:

The processes that generated these salts preclude organics (size reduction will not alter the concentration of hazardous constituents)

One purpose of the sampling and analysis program is to confirm data concerning processes that generated the wastes. The process of reducing the size of the particles, and mixing and sampling them using the ASTM C702-93 methods greatly increases opportunity for volatile compounds to escape from the sample before further analysis. Thus, confirmation that there are no volatile organic waste hazardous constituents in the salt is somewhat compromised, and the quality of the acceptable knowledge becomes the controlling factor in acceptance of these salt residues. This change would not be allowed by the WAP, but its technical impact would seem to be marginal unless the acceptable knowledge is inadequate.

5. An August 26, 1998, CAO letter (Hunter 1998e) grants RFETS a similar exemption for ash residues, noting:

It must be demonstrated that mechanical blending will not significantly affect the concentration of constituents in the sampled material. This 
can be shown by analysis of smaller particles compared with material analyzed after size reduction and blending or by acceptable knowledge demonstrating that volatile constituents will not be present in the waste.

This statement misses one of the principal purposes of sampling and analysis waste characterization, to confirm acceptable knowledge. If acceptable knowledge was used to meet the additional requirement imposed by the $\mathrm{CAO}$ then acceptable knowledge is being used to confirm itself.

The Final Environmental Impact Statement on Management of Certain Plutonium Residues and Scrub Alloy Stored at the Rocky Flats Environmental Technology Site (US DOE 1998a) notes that several types of ash residues contain organic material (Volume 2, Section B.3.2, p. B-10). Any pre-Permit ash residues characterized using only acceptable knowledge do not meet WAP requirements. However, the presence of these organic materials was established by chemical analyses that are a part of the acceptable knowledge record; since neither the individual concentrations nor total amount of organic material in the ash residues are likely to be affected by reanalysis to any significant degree, the impact of this change is likely insignificant.

\subsubsection{WAP Radiography QAOs}

The WAP Section B3-4 QAOs for radiography are not all in the QAPP QAOs or other documents. Those that cannot be found or differ from the WAP are as follows:

1. The WAP requires that if the QAOs are not met, then corrective action is to be taken. The QAPP Section 10.1 (p. 10-1) contains a similar statement, but the QAPP QAOs are not the same as the WAP QAOs. However, any of the WAP QAOs that are contained in other QAPP requirements would fall under the corrective action plan specified by the CAO's Quality Assurance Program Document (US DOE 1996b and US DOE 1998b), which is applicable at the waste generating/storage sites where waste will be characterized. 
2. A WAP radiography precision $\mathrm{QAO}$ is to verify precision prior to use in waste characterization by viewing an image test pattern to demonstrate compliance with QAOs. Though Section 10.5 of the QAPP requires visualization of a test pattern image prior to use (p. 10-9), it does not require the test pattern check to demonstrate compliance with QAOs. However, none of the WAP QAOs establish visualization criteria for real-time radiography (RTR) beyond the ability to visualize prohibited items and identify waste matrix items; in practical terms, there is no difference between the WAP QAO and the QAPP requirement.

3. A WAP radiography accuracy QAO requires the Site Project QA Officer to calculate and report the miscertification rate of waste containers that are assigned to a different waste matrix code, or are found to contain prohibited items, when visually examined. The QAPP accuracy QAO does not require inclusion of prohibited items in calculating miscertification rates (Section 10.1, p. 10-1):

The accuracy with which the matrix parameter category and waste material parameter weights can be determined must be documented through visual examination of a randomly selected statistical portion of waste containers (Section 5.4.2). The percentage of waste containers which requires a new matrix parameter category after visual examination must be calculated and reported by the site project QA officer as a measure of radiography accuracy.

In the QAPP, there appears to be an attempt to separate radiography performed for RCRA purposes from radiography performed to meet transportation requirements. Section 5.4.2 of the QAPP, where calculation of miscertification rates is described, contains the following statements (p. 5-18):

The data obtained from the visual examination must also be used to determine, with acceptable confidence, the percentage of miscertified waste containers. Miscertified containers are those that radiography indicates meet the WIPP-WAC radiography-determined and TRAMPAC requirements [sic] but visual examination indicates do not meet these requirements. Note that the radiography requirements of 
Section 10.0 are separate from the radiography requirements of WIPPWAC and TRAMPAC certification.

Since the TRAMPAC (TRUPACT-II Authorized Methods for Payload Control) certification requires checking for prohibited items, there may have been an interpretation that a miscertification rate could be calculated for prohibited items for transportation concerns, and a second miscertification rate calculated from errors in applying waste matrix codes. If so, no great effort was made to clearly establish this distinction in the QAPP.

Despite the discussion above, it should be noted that the calculated rate of miscertifications at LANL included prohibited item discoveries. This calculation was used to change the initial miscertification rate for all sites in the Permit--another contentious issue that is included in the DOE lawsuits on the Permit.

4. A WAP Radiography DQO requires that RTR recordings and data forms be validated as indicated in Section B3-10; Section B3-10 contains a requirement that radiography tapes be (p. 3-24):

....reviewed on a waste container basis at a minimum of once per testing batch or once per day of operation, whichever is more frequent. The radiography tape will be reviewed against the data reported on the radiography form to ensure that the data are correct and complete.

A "testing batch" can be up to 20 waste containers. The comparable QAPP requirement specifies that at a minimum the tape from every $10^{\text {th }}$ waste container is to be reviewed (Section 3.1.1, p. 3-3). The pre-Permit characterization may have been more conservative than the WAP requirements, or less conservative, depending on the number of waste containers radiographed each day. 


\subsubsection{Deviation From QAPP Waste Characterization Sampling Requirements For Radiography}

Table 10-1 of the QAPP lists the waste material parameters types for which QAPP Section 10.1 states weights are to be estimated. A May 8, 1998, CAO letter to LANL (Stroud 1998) notes that RTR operators should attempt to estimate weights in terms of the Table 10-1 list, but also allows the operators to combine categories into more general descriptions when individual types cannot be easily distinguished. One example given is to combine cellulose, rubber, and plastic materials into a single classification.

WAP Table B3-1 is identical to QAPP Table 10-1, and there are no provisions in the WAP (as there were not in the QAPP) for alternative methods of classifying the waste. Confirmation of radiography by visual examination is required (both in the WAP and the QAPP) to compare waste material parameter weights, with no provisions for combined categories. The discussions in both documents emphasize that radiography operators are to be trained to make judgments based on the material parameter weights.

However, the material parameter wastes are not hazardous wastes, and are apparently only included in the WAP because the DOE's application contained these requirements. Waste material parameters were originally included in WIPP documents because of the effects these materials might have on the radionuclide component of the waste for long-term repository performance. There are no requirements in the WAP or in the rest of the RCRA permit concerning material parameter weights other than those listed above--no calculations to be performed, no assessment of the effect these components would have on hazardous materials, no required considerations of how these materials might become hazardous wastes. The effect of this deviation is therefore negligible. 


\subsubsection{Total VOC Analysis QAOs (Section B3-6)}

Total VOCs are collected from homogeneous solids and soil/gravel; VOC considerations for the pyrochemical salt wastes emplaced in the WIPP during the pre-Permit period are described in the headspace gas QAO discussion above. Other homogeneous solids have been characterized under the pre-Permit WIPP waste characterization program at INEEL, and there are differences between the WAP requirements and the pre-Permit characterization program. These are as follows:

1. Initial calibration requirements for GC/MS equipment appear to be slightly tighter in the WAP than in the pre-Permit waste characterization requirements. The WAP Table B3-5, referenced by both accuracy and calibration QAOs in Section B3-6, adds a requirement that the System Performance Check Compounds (SPCCs) have a minimum average response factor (RRF) as specified in the SW-846 method used, and an RRF $\geq 0.01$ for all other compounds, for the initial 5-standard calibration. These requirements are not a part of initial calibration criteria in the comparable table in the QAPP (Table 13-3). However, the QAPP table does require that the SPCCs exceed the current SW-846 requirements during the continuing calibration checks that are performed at the beginning of every 12 hours of operation.

2. One portion of the initial calibration requirements for GC/FID equipment was significantly changed from those in the pre-Permit waste characterization program. The WAP Table B35 requires the calibration curve correlation coefficient to be greater than 0.990 or the percent relative standard deviation (\%RSD) be less than 20 for all analytes in comparing results from the three different standards used in the calibration; the QAPP specifies the correlation coefficient must be greater then 0.93 , or the \%RSD be less than or equal to 35 . The Transuranic Waste Characterization Sampling and Analysis Methods Manual (US DOE 1996c), however, specifies a \%RSD $\leq 20$ in the GC/FID methods (440.1 and 440.2), and was a requirements document during the period pre-Permit wastes were characterized. 
SW-846 Method 8000 clearly states (Section 7.5.2; the GC/FID Method 8015 references Method 8000 for calibration requirements):

The regression calculation will generate a correlation coefficient ( $\mathrm{r}$ ) that is a measure of the "goodness of fit" of the regression line to the data. A value of 1.00 indicates a perfect fit. In order to be used for quantitative purposes, $\mathrm{r}$ must be greater than or equal to 0.99 .

Any use of GC/FID during the pre-Permit characterization of wastes that utilized the correlation coefficient method specified in the QAPP would seem to be questionable. It may be that GC/FID was not used for WIPP pre-Permit waste processing.

3. Section B3-6 of the WAP requires that laboratory blanks be assessed to determine laboratory contamination, and that these trigger corrective action when control limits are exceeded. The WIPP pre-Permit waste characterization was performance-based in this respect--if laboratory blanks failed to meet criteria (the same criteria that are in the WAP), then corrective action (a nonconformance report) was to be initiated, but there was no requirement that the lab specifically assess possible laboratory contamination.

4. The Section B3-6 total VOC analysis completeness QAO defines valid results as results that meet not only precision, accuracy, completeness and detection limit criteria, but also the criteria for calibration, representativeness, and comparability found in the section. The QAPP defines valid results in terms of meeting the Table 13-1 criteria, which only specify precision, accuracy, completeness and detection limit boundaries.

5. A Section B3-6 total VOC analysis comparability $Q A O$ requires waste characterization to use SW-846 sample preparation methods; the QAPP merely specifies standard methods. However, since the WIPP pre-Permit waste characterization program also specified use of the WIPP Methods Manual (US DOE 1996c), which was based on the SW-846 methods, the differences are likely minimal. 
6. A Section B3-6 total VOC analysis comparability QAO requires that all waste characterization sites successfully participate in the PDP. This requirement is addressed in Section 2.3.3, Item 5, of this report

7. A Section B3-6 total VOC analysis representativeness $Q A O$ requires that samples be collected as described in the Permit Attachment B1. Section B1-2a(2) includes a requirement that cores are to be divided into three equal-length subsections, and a subsample is to be taken from random locations in each of the three subsection. The subsamples are then to be combined for analysis. The pre-Permit waste characterization program specified only a single sampling site randomly chosen from the entire length of the core.

This difference has been deemed by the DOE to be significant enough that it was included in both the DOE federal and state court lawsuits on the WIPP RCRA permit, in an apparent effort to eliminate re-sampling of homogeneous drums that have already been characterized. Since some of the homogeneous solidified drums were created with multiple processes--that is, a mixture of waste and solidifying agent were poured in and allowed to harden, then later other similar mixtures were added--and stratification by settling may be a factor in sludge drums stored over long periods, the RCRA permit three sub-sample system may seem to produce a more representative sample. However, the SW846 description of sampling (Chapter 9) does not address such sub-sampling. In fact, SW846 states that simple random sampling is likely the better method unless nonrandom heterogeneity is known to exist (Chapter 9, pp. 8-9). If such knowledge is available, then SW-846 indicates that the specific strata are to be sampled, implying separate analyses rather than the compositing required by the permit. In brief, neither the pre-Permit sampling nor the WAP method seem to be entirely in accord with the RCRA sampling guidelines outlined in SW-846. Without evidence of nonrandom heterogeneity, however, the pre-Permit sampling process does seem to be closer to SW-846 guidelines than those included in the RCRA permit. 


\subsubsection{Total Semivolatile Organic Compound (SVOC) Analysis QAOs (Section B3-7)}

All SVOC pre-Permit waste characterization differences from the WAP QAOs are directly analogous to individual total VOC differences as discussed for the QAOs from WAP Section B36. The same minor calibration concerns for GC/MS is present for GC/ECD (see item 1 discussion in VOC analysis $\mathrm{QAO}$ in Section 2.3.7), the requirements differences for GC/ECD was discussed in item 2 for GC/FID, the pre-Permit program did not require assessment of laboratory contamination (item 3), the pre-Permit requirement was only to participate in the PDP rather than to successfully participate (item 6), and samples were taken from a single core site in homogeneous solids rather than the three sub-sampling areas required by the permit (item 7). For homogeneous solids SVOC sampling, however, both the QAPP and the WAP specify the same alternative ASTM procedure may be used instead of the three sub-sample requirement.

\subsubsection{Total Metal Analysis QAOs (Section B3-8)}

The WAP metal analysis QAOs contain some unique differences from the QAPP, but most of the differences are analogous to deviations discussed above. These anomalies are as follows:

1. Daily calibration requirements for inductively coupled plasma-mass spectroscopy (ICPMS) in the WAP (Table B3-9) specify that the replicate \%RSD be $\leq 5$, whereas the QAPP Table 15-4 requires only $\leq 10 \%$ RSD. For the same daily calibration, the WAP requirement for mass calibration is that it be within $0.9 \mathrm{amu}$, with a resolution of $<1.0 \mathrm{amu}$ full width at $10 \%$ of the peak height, while the QAPP specified 0.1 amu for the mass calibration. Both the WAP and the QAPP require nonconformance reports to be written if these requirements are not met.

The WAP requirement for the \%RSD appears to be based on a misinterpretation of the SW-846 method (Method 8020). The method requires in Section 7.4 that the 5\% RSD be established for four replicate measurements to verify that the ICP-MS instrument has reached an equilibrium before performing the calibrations specified in 
Section 7.5 and 7.6. The implication is that if the 5\% RSD is exceeded then more time should be allowed to reach equilibration, and new measurements taken and compared--the $5 \%$ RSD is simply to verify that the instrument is ready for calibration. Immediately after calibration, the method requires in section 7.8 that verification of calibrations to be within $10 \%$, or analyses are to be terminated and corrective actions are to be instituted.

The WAP 0.9 atomic mass unit ( $\mathrm{amu}$ ) mass calibration requirement also seems to be a misinterpretation of Method 8020. Method 8020 specifies $0.1 \mathrm{amu}$ for mass calibration in Section 7.5, the same as in the QAPP; the section also requires $\leq 0.9 \mathrm{amu}$ full width at $10 \%$ of peak height as an additional requirement--but this is not the mass calibration. Note that both the WAP and QAPP requirements exceed the full width at $10 \%$ of peak height requirement slightly.

As the QAPP requirements are nearly in accord with the SW-846 method, and the WAP QAO seems to be unsupported, the technical significance of this difference would seem to be very slight.

2. A WAP metal analysis QAO adds a requirement that "laboratory sample duplicates" be assessed for precision as well as the QAPP-required laboratory matrix spike duplicates, replicate analysis of laboratory-control samples, and PDP blind-audit samples. However, the WAP contains no definition for "laboratory sample duplicates", so that without clarification these appear to be merely a subset of the "replicate analyses of laboratorycontrol samples" found in both the WAP and the QAPP.

3. A WAP metal analysis accuracy QAO adds "serial dilutions" and "interference check" samples to the QAPP list (laboratory matrix spikes, PDP blind-audit samples, and laboratory-control samples) that must be analyzed for accuracy. 
The addition is technically significant, and would increase confidence in the accuracy of metal measurements. SW-846 Method 6020 (for ICP-MS, one of the more commonly used analysis instruments for metal analysis) clearly requires (Section 8.4) that interference checks must be made in order to perform measurements correctly, and states that dilution tests for each batch of each matrix must also be performed (Section 8.5). The Method Manual Procedure 630.1, Section 10.1, also clearly states that these steps of Method 6020 are to be followed. While the EEG has not checked all Methods Manual procedures for all types of metals analysis instrumentation it seems probable that the WAP QAO would be met by following the required Methods Manual procedures. However, the results would not likely be reported as a part of the accuracy determination.

4. As with the WAP headspace VOC QAOs and homogeneous waste VOC and SVOC QAOs, there is a metals analysis QAO related to laboratory contamination. The discussion in Section 2.3.7, Item 3, also applies to the analogous metals QAO in this section.

5. A WAP comparability QAO for total metals analysis requires that SW-846 sample preparation methods be used; the QAPP merely specifies standardized methods.

The QAPP Table 15-2, Total Metal Analytical Methods, specifies only SW-846 methods, implying compliance with the WAP QAO. However, the QAPP also allows alternative methods to be proposed to $\mathrm{CAO}$, and the Preface to the Methods Manual specifies the submittal and approval process to be followed (this process was submitted as a part of the Permit application, but is not a part of the Permit). While it is not clear that the Methods Manual process was used, CAO has granted RFETS approval of an alternative method for metals analysis sample preparation (Hunter 1998a)--but the method is an SW-846 Method (3050).

6. A WAP representativeness $\mathrm{QAO}$ for total metals analysis requires the collection and preparation of samples in the laboratory be performed using "representative and unbiased methods." The QAPP contains no comparable statement. 
The WAP contains no characteristics or criteria for unbiased methods. As cited above, the QAPP required use of SW-846 methods for total metals analysis, and use of these procedures are accepted throughout the WAP. Pre-Permit analyses for total metals are unlikely to be affected by this additional requirement.

\subsubsection{Acceptable Knowledge}

The importance of acceptable knowledge (AK) is noted by the DQOs, in that all other waste characterization activities are used principally to ascertain the validity of $\mathrm{AK}$ conclusions. Section B3-9 of the WAP notes that acceptable knowledge provides qualitative information that is not amenable to assessment according to specific data quality goals; however, the section does list data quality requirements for precision, accuracy, completeness, comparability, and representativeness, all of which were considered for the various analytical techniques considered above. Differences between the pre-Permit acceptable knowledge data quality goals and those listed in the WAP are as follows:

1. The WAP requires the Permittees (the $\mathrm{CAO}$, and the Waste Isolation Division currently managed by Westinghouse Corporation) to perform a "Final Confirmation" that appropriate analytical and testing results are used to confirm the characterization of wastes based on acceptable knowledge (referencing Section B4-4 of Permit Attachment B-4). The QAPP (Section 3.1.3) required only that the CAO verify that data packages contained specified information, without confirming the appropriateness of the data.

While the change in required roles for $\mathrm{CAO}$ is significant, the effect on pre-Permit waste characterization would likely be insignificant. Since the Hazardous Waste Permit does not directly control out-of-state generator sites, this WAP requirement may have been added to provide a basis for regulatory action if appropriate results were found to be lacking. 
2. Section B3-9 requires, as a part of the comparability data quality requirements, that sites are to assign hazardous waste codes "...in accordance with Permit Attachment B4-4...." Permit Attachment B4-4 is titled Additional Final Confirmation of Acceptable Knowledge at the WIPP Facility, and does not specify methods for assigning hazardous waste codes, nor does there appear to be any one specific section of the WAP that does list all the criteria for assignment of hazardous waste codes. It does appear that the basic methods listed in the WAP (assign hazardous waste codes based on acceptable knowledge, apply them conservatively, use all available knowledge, follow a written procedure for assigning hazardous waste codes, etc.) are a part of Chapter 4 of the QAPP.

3. Another requirement of Section B3-9 is that any inconsistencies between acceptable knowledge documentation and results of confirmatory analytical techniques (chemical analysis, radiography, or visual examination) are to be reported to CAO/WID within 5 days (written report) followed by a nonconformance report within 30 days. The pre-Permit waste characterization program had no such reporting requirements. The effect of this difference would seem to be minimal, as in both cases the site remains responsible for assessing and correcting the inconsistency before certifying affected waste for shipment to the WIPP.

4. Section B3-9 requires tracking of inconsistencies within acceptable knowledge data and documenting the results of acceptable knowledge confirmation from the confirmatory analytical techniques. The pre-Permit process did not require this tracking and documentation, but the QAPP does briefly cover consequences of consistent discrepancies with acceptable knowledge information (Section 4.4.4). The tracking and documenting required by the WAP would seem to be an important and useful process, but would also seem likely to have only minimal impact on pre-Permit waste characterization activities. 


\subsubsection{QAO Relating to Pre-Permit Waste Analysis Procedures Based on Deleted SW- 846 Methods}

The WAP includes a comparability QAO for each type of analytical process (VOC, total VOC, SVOC, and metals) stated as follows:

Any changes to SW-846 methodology that results in the elimination of sample preparation or analytical methods in use at generator/storage sites must be addressed as a corrective action to address the comparability of data before and after the SW846 modification.

Final Update III (December 1996) to SW-846 lists several procedures that were deleted in that update (see p. 7 of Instructions). The procedures were not superseded--they were simply removed, with no explanation provided. Among the deleted procedures are:

8240B Volatile Organics by Gas Chromatography/Mass Spectrometry (GC/MS) 8250A Semivolatile Organic Compounds by Gas Chromatography/Mass Spectroscopy (GC/MS)

These two methods are major constituents of procedures for VOC, total VOC, and SVOC in the Methods Manual, in use during the pre-Permit waste characterization period (the last update of the Methods Manual was Revision 1, approved in April 1996). The two deleted SW-846 methods listed above were used in the Methods Manual as follows:

1. Methods Manual Procedure 430.2, Modified Method 8240B/8260A for the Determination of Volatile Organic Compounds in Waste Container Headspace used 8240B with 8460A (still in SW-846) as its basis. Method 430.2 states (Section 1.2, p. 1),

This procedure only details the sections of SW-846 Methods 8240B and $8260 \mathrm{~A}$ that need to be modified to allow the analysis of gas samples. Analysts must refer to SW-846 Methods $84240 \mathrm{~B}$ and $8260 \mathrm{~A}$ for additional guidance. 
It may be that the Method $8240 \mathrm{~B}$ and $8260 \mathrm{~A}$ were sufficiently identical that the deletion of $8240 \mathrm{~A}$ would have minor, if any, effect on the quality of pre-Permit headspace gas measurements for WIPP wastes. It also may be possible that the Method 430.2 was not used, as the Methods Manual contains another method (Method 430.1) which could also be used to analyze headspace VOCs.

2. Methods Manual Procedure 430.3, Method 8240 B for the determination of Total Volatile Organic Compounds in Homogeneous Solids and Soil/Gravel, is completely dependant on SW-846 Method 8240B for total VOC analysis. Section 1.2 states that the analyst should refer to SW-846 Method 8240B for the "specific requirements of this procedure"; Section 8.0, which contains the specific procedural steps to be followed, simply refers the analyst to steps in $8240 \mathrm{~B}$.

Procedure 430.3 is not the only method for total VOC analysis in the Methods Manual-430.4, based on SW-846 Method 8260A, could also be used. However, it appears that any pre-Permit homogeneous waste analysis for total VOCs performed in accordance with 430.3 was not in compliance with the EPA guidelines required in the RCRA permit.

3. Methods Manual Procedure 430.5, Method 8250A for the Determination of Total Semivolatile Organic Compounds in Homogeneous Solids and Soil/Gravel, is completely dependant on SW-846 Method 8250A for total VOC analysis. The statements in Section 1.2 and Section 8.0 are the same as those in 430.3 , only changing the references to Method 8250 A. Similarly, there is another Methods Manual Procedure that could be used for SVOC analysis (430.6); however, as with 430.3, any analyses that may have been performed using 430.5 do not appear to have been performed in accordance with the EPA guidelines required in the RCRA permit.

If utilized at all, the impact of the deleted SW-846 methods on waste characterization during pre-Permit waste characterization may not seem to be of major significance. The deleted methods were initially promulgated by the EPA, and were current at the time the 
last update to the Methods Manual was made. It is unfortunate that SW-846 does not list the reasons for deleting the procedures; however, since the reasoning is not supplied, it is unlikely that the procedures contained any major defects.

It would also be unfortunate if the DOE did not ensure that required methods were in conformance with EPA guidelines when WIPP waste characterization activities were performed. A CAO letter to some of the sites (Watkins 1997) states (p. 2):

Several SW-846 methods which the Methods Manual is based on have been revised. Sites can update their procedures to the latest SW-846 procedure. When SW-846 is revised, the latest information should be included in site procedures and in the Methods Manual as soon as practical.

The philosophy espoused is in conformance with the WAP, but the Methods Manual had not been updated two years later in November 1999. The letter does not inform other waste generator sites of the change. It may be that individual laboratories characterizing wastes noted the deletion of the two applicable SW-846 methods and used the Methods Manual alternative procedures.

\subsubsection{QAOs Related to Data Usability Criteria}

Data usability criteria are required to be met for headspace gas and homogenous solids sampling, and analysis for VOCs, total VOCs, SVOCs, and metals. The requirement is specified either as a part of the completeness requirements (VOC and SVOC) or the comparability requirements (all others). The requirement for data usability consideration is in Section B3-1 (p. B3-4) as follows:

The comparability of waste characterization data shall be ensured through the use of generator/storage site data usability criteria. The Permittees shall ensure that data usability criteria are consistently established and used by the generator/storage sites to assess the usability of analytical and testing data. The criteria shall address, as appropriate, the following:

- Definition or reference of criteria used to define and assign data qualifier flags based on Quality Assurance Objective results, 
- Criteria for assessing the usability of data impacted by matrix interferences,

- Criteria for assessing the usability of data based upon positive and negative bias as indicated by quality control data, of data qualifiers, and qualifier flags,

- Criteria for assessing the usability of data due to

- Severe matrix effects,

- Misidentification of compounds,

- Gross exceedance of holding times,

- Failure to meet calibration or tune criteria

- Criteria for assessing the usability of data that does not meet minimum detection limit requirements.

The Permittees shall be responsible for evaluating generator/storage site data usability and shall assess implementation through the generator/storage site audit.

There are no comparable requirements in the QAPP for establishing criteria related to data usability. However, it should be noted that in the pre-Permit waste characterization process data which failed to meet QAOs or other expected results became a part of the nonconformance process as specified in the QAPP Section 2.1.2.1. Nonconformance reports were required to provide "...an indication of the potential ramifications and overall usability [of] the data, if applicable" (QAPP, p. 2-4). The effect of the lack of requirements for data usability criteria would seem to be minimal.

\subsubsection{SW-846 Modification and Representativeness QAOs}

The WAP includes a representativeness QAO for each type of analytical process (VOC, total VOC, SVOC, and metals) stated as follows:

Any changes to SW-846 methodology that results in the elimination of sample preparation or analytical methods in use at generator/storage sites must be addressed as a corrective action to address the comparability of data before and after the SW-846 modification.

The QAPP does not contain any comparable statements. However, the Methods Manual requires that specific versions of SW-846 methods be followed (US EPA 1996), so that the possibility of 
changing from one method to its revision was not a part of the pre-Permit waste characterization program.

\subsubsection{Cancellation of Corrective Action Reports Related to the QAPP and Methods Manual}

A January 18, 2000, CAO memorandum (Vega 2000) closed a series of Corrective Action Reports (CARs) from the pre-Permit waste characterization program, based on the argument that the cancellation of the QAPP and Methods Manual eliminated the requirements the CARs were written against. CARs cancelled include five for INEEL, five for LANL, and none from the RFETS program.

Many, if not all, of these CARs relate to QAPP and/or Methods Manual practices that are required by the WAP. For instance, two of the cancelled INEEL CARs (US DOE 1999d and US DOE 1999e) concerns inadequate sample handling and custody control, a necessary consideration for hazardous waste samples; WAP Attachment B1-4 contains requirements that cover the same area. WAP Attachment B13-4 requires that identified corrective actions be examined for the extent and cause of the deficiency, and that remedial actions to preclude recurrence be planned, reported, completed, and verified before closure of the CAR. Since this process was apparently not completed for the CARs at INEEL and LANL, the pre-Permit waste characterization program cannot be said to be in accordance with the WAP. The significance of this deviation from WAP requirements cannot be accurately assessed without examining the extent and cause of the deficiencies for each of the CARs pertinent to characterization of hazardous waste.

\subsection{Conclusions and Recommendations}

1. The WAP appears to have made explicit many of the undocumented assumptions and implied good practices from the DOE's pre-Permit waste characterization program as specified in the TRU Waste Characterization QAPP. 
2. There appears, on the surface, to be significant differences between the pre-Permit waste characterization program and the WAP requirements. A more thorough technical review, however, shows that the essence of the requirements appear to have been met despite the apparent differences. The pre-Permit waste analysis process appears to meet the bulk of the technical requirements in the WAP.

3. Deviations from the fundamental documentation of the pre-Permit waste characterization program may be the most pertinent differences from WAP requirements. Variances from the requirements were not fully documented. Though it is unlikely that most of these would be major differences from WAP requirements, there remains the potential that at least some of these--solid coring, failure to sample headspace gases, drum temperature equilibration and perhaps others-- may be a factor in consideration of pre-Permit wastes. The premature closure of independent audit corrective actions for numerous deficiencies at INEEL and LANL, and the possibility that internal audit corrective actions may also have been cancelled or prematurely closed, may also create a perception that pre-Permit wastes were not characterized in accordance with the WAP.

4. There are enough known differences between the pre-Permit program and the WAP that, should the IV.B.2.b requirement become an issue, the data for the individual container lot sampling and analysis could be reviewed to determine compliance or noncompliance with the WAP. Since some of the evidence of compliance might not be easily deciphered, representatives from the DOE could be allowed to be present during the review so as to be able to point out data that might cover requirements. The Hazardous Waste Permit regulators would make the final determination. 


\section{RISK ANALYSIS FROM ROUTINE OPERATIONS}

\subsection{Introduction}

The risks from emplacement of wastes at WIPP during routine (non-accident) operations are from: (1) external radiation received by those involved in waste handling operations; and (2) inhalation of VOCs that emanate from the filtered waste drums and boxes. Persons that might be exposed to VOCs include underground workers that are down wind from waste storage rooms, surface workers who may be exposed to discharges from the exhaust ventilation shaft, and members of the public that are off-site.

Risks from VOCs, hazardous metals, and radionuclides were evaluated for routine and accident conditions in EEG-72 (Channell and Neill 1999) and in the WIPP Safety Analysis Report (SAR) (US DOE 1999a) for full repository conditions. DOE's Application to NMED (the Application) (US DOE 1997) for the Permit evaluated risks from VOCs for routine and accident conditions.

The purpose of this analysis is to compare the risk from pre-Permit wastes in the repository with WAP-certified wastes that are to be emplaced after the Permit is issued. The routine operations analysis presented in this report will not include risks from radionuclides or hazardous metals. Radionuclide analyses are not included in the WAP and the external radiation doses received during waste emplacement will be incurred regardless of when the wastes are emplaced. Hazardous metal analyses and/or acceptable knowledge are required by the WAP, but the results are not used to calculate risks or set control limits. Also, no hazardous metal exposures are expected during routine operations.

\subsection{Scenario Assumptions}

The pre-Permit waste containers were emplaced in the exit drift (south $1600 \mathrm{Drift}$ ) portion of Room 7 of Panel 1. There is a temporary metal bulkhead with 2 louvers for flow of ventilation 
air from the downstream portion of the room. Ventilation air at a rate of 35,000 cubic feet per minute ( $\mathrm{cfm}$ ) flows from the working face of the emplacement stack over the waste, through the louvers, down the south 1600 drift to the east 300 drift and up the exhaust shaft. An exhaust shaft flow rate of $260,000 \mathrm{cfm}$ is used in these calculations ${ }^{7}$ (see Figures 3.1 and 3.2). Scenario assumptions are almost identical to those used in EEG-72 and the Application.

Underground workers are exposed to VOC emissions from Room 7 while changing filters on the continuous air monitors (CAMs) located on the downstream side of the temporary metal bulkhead. In the Permit, NMED set room based concentration limits (RBCLs) on VOCs in order to protect the underground worker from lower explosive limit (LEL) and immediately dangerous to life and health (IDLH) concentrations due to a roof fall accident but not from long-term carcinogenic or non-carcinogenic risks (NMED 1999a). This report will calculate the carcinogenic and non-carcinogenic risks to underground workers.

The expected risk from VOCs to persons above ground during WIPP's operating lifetime is assumed to be due to emissions from all waste emplaced in open rooms, closed rooms, and closed panels. These risk calculations assume that containers with average concentrations of VOCs are emplaced at an average rate for the repository's operating lifetime (US DOE 1997). Emissions from a full open room have been estimated to be about 125 times those from a full closed room for carcinogenic VOCs and 75 times for non-carcinogenic VOCs (Channell and Neill 1999). Thus, the only way risks can be greater than expected is from either: (1) bringing in containers with above average concentrations of VOCs early (because they will emanate longer through closed rooms and panels); and (2) leaving waste in an open room for a longer than average period.

${ }^{7}$ The Permit requires a minimum running annual average mine ventilation exhaust rate of 260,000 standard $\mathrm{cfm}$ and a minimum active room ventilation rate of 35,000 standard $\mathrm{cfm}$ when workers are present (Section IV.E.3.b). At present an exhaust ventilation rate of $425,000 \mathrm{cfm}$ is typical. The use of $260,000 \mathrm{cfm}$ is conservative (i.e., it leads to higher calculated above ground concentrations). 


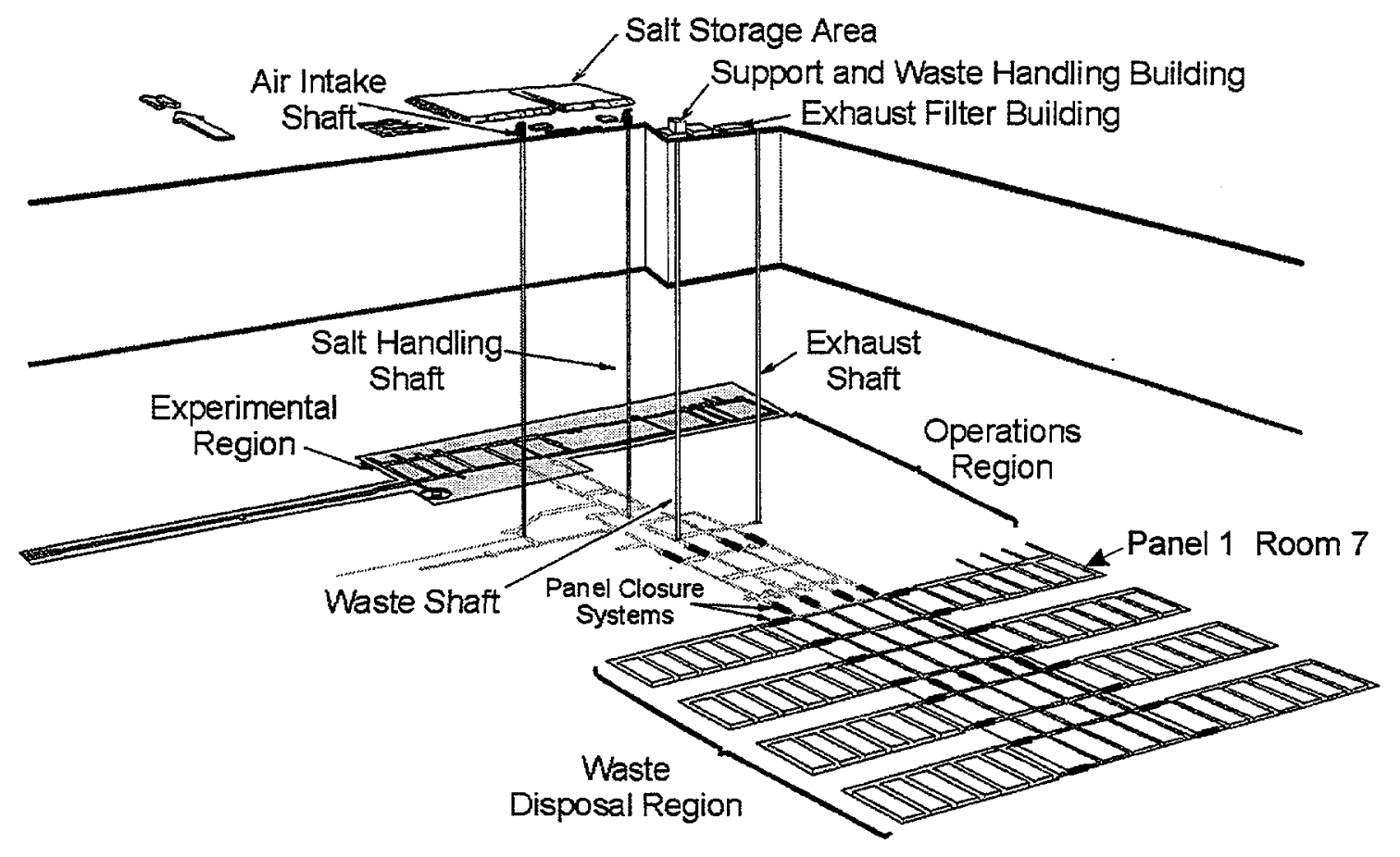

Note: For illustrative purposes only. Not to scale.

Figure 3-1. The WIPP facility includes surface support buildings, a waste handling building, four shafts, and the mined underground operations area. The repository is located approximately $658 \mathrm{~m}(2150 \mathrm{ft})$ below the surface, within the Salado Formation, a Permian sequence of bedded salt with minor amounts of anhydrite and clay. The excavations are accessible from the surface by four verticle shafts. Only one of the eight panels has been excavated to date. Each panel consistes of seven rectangular rooms, $10 \mathrm{~m}$ wide and $91 \mathrm{~m}$ long, separated by $30.5 \mathrm{~m}$ wide pillars. Source: DOE 1996b 


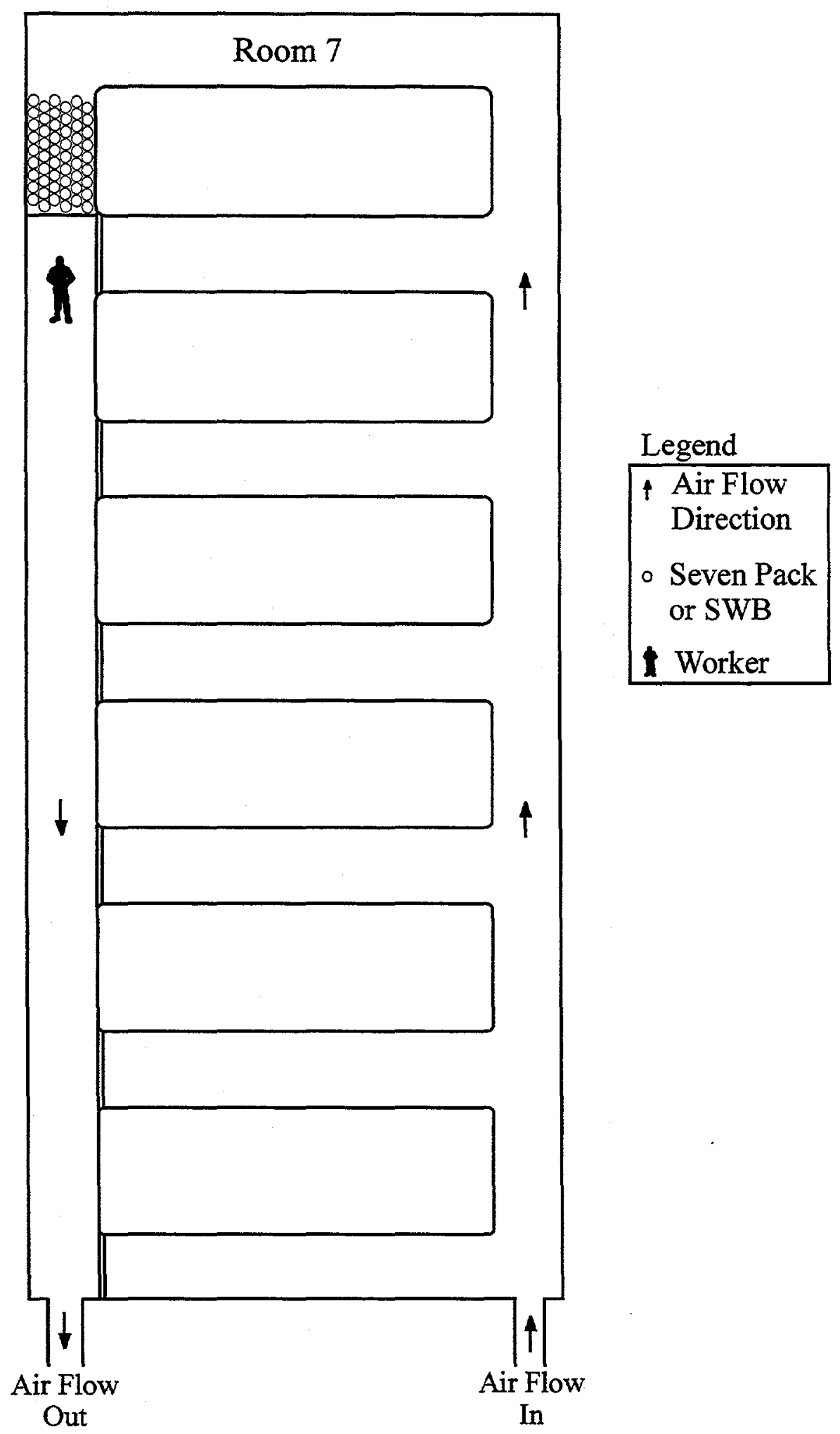

Figure 3-2. Waste Emplacement Process (Source: DOE 1999). 
Pre-Permit waste containers emplaced in Room 7 have a lower than average VOC concentration. However, the early emplacement has resulted in the room being left open longer because of the slow shipping rate and the November 1999 - March 2000 period when shipments were not allowed. A waste room will be filled in about six months at the average 35-year emplacement rate. WIPP received its first waste on March 26, 1999, and Room 7 will probably not be filled and closed before early 2001. Bringing in pre-Permit waste early will probably cause open room exposure conditions to exist for approximately 12 additional months. The emissions from Room 7 during this additional one-year period are assumed to be a new source of exposure that was caused by bringing in pre-Permit waste.

\subsection{Determination of VOC Source Term}

In determining the VOC source term it was assumed that the values measured in the pre-Permit waste containers are accurate. Obviously one cannot be certain of the accuracy of non-WAP certified waste. However, the analysis in Chapter 2 suggests the analysis is probably similar and acceptable knowledge indicates that VOC concentrations in non-mixed waste should be low.

Chapter 3.5 provides a bounding risk for the assumption that VOC concentrations are completely unreliable.

The VOC source term was determined from all the wastes emplaced in Room 7 as of October 25, 1999. VOC concentrations are from the WIPP Waste Information System (WWIS), a DOE database that includes waste characterization data for each waste container. The total waste emplaced was: (1) 101 Standard Waste Boxes from LANL; 126 drums of graphite wastes from the INEEL; and 408 drums of residues and 26 drums of graphite waste from RFETS. An additional 166 RFETS residue drums were received before the Permit became effective. These additional shipments were ignored because the exact number was unknown at the time the calculations were performed and the effect would be minor (e.g., 166 additional RFETS residue drums would increase carcinogenic risk by about $8 \%$ and non-carcinogenic risk by about $3 \%$ ). 
Reported VOC concentrations are low in all cases (as would be expected for non-mixed wastes). Most VOC measurements were less than the minimum detectable concentration (MDC) and only four had any values greater than the PRQL.

Only five of the approximately 25 VOCs analyzed were retained for the risk analyses. Those retained had a fair percentage of $J$ values (greater than the MDC, but less than the PRQL, and considered to be detected) and average concentrations from at least one of the three generating sites of about $1 \mathrm{ppmv}$ or greater. Two flammable VOCs that met these criteria (acetone and methanol) are not considered by EPA to have carcinogenic or non-carcinogenic risks and were also deleted from the risk analysis. The VOCs used along with their weighted average concentrations are shown in Table 3-1. Only three of these VOCs (methylene chloride, toluene, and 1,1,1-Trichloromethane) are among the nine VOCs listed in the Permit. Details of the calculation are in Appendix A.

Table 3-1. VOCs Used in Risk Analysis

\begin{tabular}{|l|c|c|}
\hline \multicolumn{1}{|c|}{ VOC } & Health Effect & Average Concentration ppmv \\
\hline Methylene Chloride & carcinogen & 0.41 \\
\hline Benzene & carcinogen & 0.39 \\
\hline $1,1,1-$ Trichloromethane & non-carcinogen & 2.9 \\
\hline Methyl Ethyl Ketone & non-carcinogen & 4.6 \\
\hline Toluene & non-carcinogen & 0.69 \\
\hline
\end{tabular}

\subsection{Risks to Surface Worker, Underground Worker, and Member of Public}

Details of the risk calculation to an on-site surface worker, an underground worker, and to a member of the public (the Maximum Individual Receptor-MIR) located at the WIPP site boundary are in Appendix A. Results are summarized in Table 3-2. These are the total estimated incremental risks during the lifetime of WIPP operations from pre-Permit wastes at the repository. 
Table 3-2. Risks to Surface Worker, Underground Worker, and Member of Public

\begin{tabular}{|c|c|c|c|}
\hline VOC & Surface Worker & MIR at Boundary & Underground Worker \\
\hline Carcinogens & & & \\
\hline Methylene Chloride & $7.20 \times 10^{-15}$ & $2.56 \times 10^{-16}$ & $2.94 \times 10^{-13}$ \\
\hline Benzene & $1.56 \times 10^{-13}$ & $5.54 \times 10^{-15}$ & $6.36 \times 10^{-12}$ \\
\hline Total Cancer Risk & $1.6 \times 10^{-13}$ & $5.8 \times 10^{-15}$ & $6.7 \times 10^{-12}$ \\
\hline Non Carcinogens & & & \\
\hline 1,1,1-Trichloromethane & $4.00 \times 10^{-10}$ & $1.42 \times 10^{-11}$ & $1.63 \times 10^{-8}$ \\
\hline Methyl Ethyl Ketone & $2.57 \times 10^{-10}$ & $9.16 \times 10^{-12}$ & $1.05 \times 10^{-8}$ \\
\hline Toluene & $1.13 \times 10^{-10}$ & $4.02 \times 10^{-12}$ & $4.52 \times 10^{-9}$ \\
\hline Hazard Index & $7.7 \times 10^{-10}$ & $2.7 \times 10^{-11}$ & $3.1 \times 10^{-8}$ \\
\hline
\end{tabular}

These risks are so low that they are difficult to comprehend. Perspectives on these values are discussed separately for carcinogens and non-carcinogens.

\subsubsection{Carcinogenic Risks}

The Permit considers the highest acceptable lifetime cancer risk from VOCs to be $1 \times 10^{-5}$ for the surface worker (called a non-involved worker) and $1 \times 10^{-6}$ for the MIR. Maximum room based concentration limits are prescribed in the Permit so that these values will not be exceeded. The calculated risks for the expected quantity of VOCs in the repository are $5.6 \times 10^{-8}$ for the underground worker, $9.7 \times 10^{-8}$ for the surface worker, and $9.4 \times 10^{-9}$ for the MIR (Channell and Neill 1999).

Allowable exposures at WIPP (25 millirem per year from routine operations) (US EPA 1997) to a member of the public from radioactive materials are equivalent to a carcinogenic risk of $3.4 \times 10^{-4}$ over the 35-year emplacement period (340 times the target risk level of VOC in the Permit). Actual risks to a real individual are expected to be less than one percent of allowable. 
Carcinogenic risks of less than $10^{-12}$ for a surface worker and $10^{-14}$ for a member of the public are seven and eight orders of magnitude below allowable Permit risk levels. They are also five and six orders of magnitude below expected lifetime risks from the entire WIPP inventory over the 35-year operating lifetime. Risks to the underground worker are four orders of magnitude less than expected from the full repository and six orders of magnitude below the allowable risk for surface workers. Actions which increase risks by less than one part in ten thousand have negligible effects.

\subsubsection{Non-Carcinogenic Risks}

The non-carcinogenic Hazard Index (HI) for the pre-Permit waste is calculated to be less than: $10^{-9}$ for the surface worker; $10^{-7}$ for the underground worker; and less than $10^{-10}$ for the public member. Values for the full inventory are estimated to be $2.4 \times 10^{-5}$ for the surface worker, $1.4 \times 10^{-5}$ for the underground worker, and $2.4 \times 10^{-6}$ for the MIR. A hazard index less than 1.0 has no real meaning because these are threshold phenomena. The calculated values for the prePermit wastes are seven to ten orders of magnitude below a hazard level and are two to four orders of magnitude below the HI values for the full repository. Hence, they are negligible.

\subsection{Bounding VOC Carcinogenic Risks}

Because the values calculated above are based on data that were not obtained under a WAPcertified program, it could be argued that the VOC concentrations and risks could be much higher. A bounding limit can be calculated from the grab samples that are taken two times a week in the exhaust ventilation drift as a part of the Confirmatory VOC Monitoring Plan (Attachment $\mathrm{N}$ of the Permit). These samples have a required sensitivity well below the concentrations of concern established in the Permit to assure that the room based concentration limits are not exceeded. The method reporting limit (MRL) values for the individual VOCs are either two or five parts per billion by volume (ppbv) for the target VOC. DOE reports all data for the nine target VOCs in its Annual Site Environmental Report (Westinghouse 1999). The three VOCs used in this report were the only ones that had any values greater than the MRL. 
Methylene chloride is the only one of our two carcinogenic VOCs that is a target VOC in the Permit (Table IV.B.1). Benzene is one of the additional VOCs that is determined in the analysis. Also, the statement is made in Appendix D-20 of the Application and Attachment $\mathrm{N}$ of the Permit: "Non-target sample contaminants identified by NIST library searches will be reported as tentatively identified compounds, and concentration calculations will be based on the response of the nearest internal standard." Based on this we assume that benzene or any other VOC detected at the 5 ppbv level would be reported.

The $5 \mathrm{ppbv}$ concentration can be considered to be the exhaust shaft concentration. The risks can then be calculated using the Appendix A methodology. Results are shown in Table 3-3.

Table 3-3. Carcinogenic Risks at MRL ${ }^{\mathrm{a}}$ Values

\begin{tabular}{|c|c|c|c|c|}
\hline \multirow[t]{2}{*}{ VOC } & \multicolumn{2}{|c|}{ MRL Values } & \multicolumn{2}{|c|}{ Carcinogenic Risks } \\
\hline & ppbv & $\mu \mathrm{g} / \mathrm{m}^{3}$ & Surface & Boundary \\
\hline Methylene Chloride & 5 & 17.4 & $3.94 \times 10^{-10}$ & $1.40 \times 10^{-11}$ \\
\hline Benzene & 5 & 16.0 & $6.40 \times 10^{-9}$ & $2.28 \times 10^{-10}$ \\
\hline \multicolumn{3}{|l|}{ TOTAL(Rounded) } & $6.8 \times 10^{-9}$ & $2.4 \times 10^{-10}$ \\
\hline
\end{tabular}

${ }^{a} \mathrm{MRL}=$ Method Reporting Limit

These risks are still low compared to the already low lifetime risks predicted from the expected quantity of VOCs emplaced in the full repository $\left(9.7 \times 10^{-8}\right.$ for the surface worker and $9.4 \times 10^{-9}$ at the site boundary, EEG-72). Thus, the Confirmatory VOC Monitoring Plan would be able to determine a lifetime risk that is $7 \%$ for the surface worker and $3 \%$ for the MIR of that expected (and accepted) in the Permit. These detectable risks are also $0.07 \%$ (surface worker) and $0.02 \%$ (MIR) of those allowed under conditions of the Permit. Clearly, if the allowed Permit risks are acceptable these risks from presently emplaced wastes are acceptable. The risk to an underground worker would be less than $3 \%$ of that allowed for the surface worker. 


\section{RISKS ANALYSIS FROM ACCIDENTS}

\subsection{Introduction}

Accidents could cause a fraction of the contents of a waste container to be released and result in exposure due to VOCs, hazardous metals, and radionuclides. The risks from a roof fall accident and a spontaneous underground fire were evaluated. Scenario assumptions are similar to those used in the 1998 SAR (DOE 1999a), in Appendix D9 of the Application, and in EEG-72. These two accident scenarios were chosen because they could both occur in the open Room 7 . Since the early emplacement of these wastes will result in the room remaining open for about one additional year, any risks resulting from these accidents can be considered an additional risk.

Other accidents considered in the SAR (e.g., drum drop, puncture, spontaneous fire in the Waste Handling Building, and hoist failure) were not evaluated. All of these accidents occur during waste receipt, handling, and emplacement and none occurred during emplacement of the prePermit wastes.

Releases evaluated from the accident scenario included VOCs and radionuclides. Hazardous metal releases were not evaluated because the average risk was found in EEG-72 to be $5 \times 10^{-7}$ of the risk from radionuclides being released (using the same release fraction assumptions). Data from sampling the LANL waste and RFETS residues indicated that the hazardous metal concentrations per drum are lower than those used in EEG-72. Hence, the hazardous metals risk should be less than $5 \times 10^{-7}$ of the radiological risk. 


\subsection{Spontaneous Fire Scenario}

\subsubsection{Scenario Description}

Spontaneous ignition was assumed to occur in a drum or SWB emplaced in Room 7. This is considered an unlikely event even for a container that does not fully conform to the WIPP Waste Acceptance Criteria (WAC) (US DOE 1999g). It is further assumed that the fire does not propagate to additional waste containers.

The methodology used in the SAR (Chapter 5 and Appendix D) to develop the probability of sustained combustion in a one-half full waste room led to an estimated frequency of $5.3 \times 10^{-6}$ per year. This calculation assumed specific percentages of each final waste form that would be processed or repackaged. The SAR assumes that processed or repackaged containers have only $10 \%$ the probability of a fire as a drum not processed or repackaged (because there is less chance of a repackaged drum not conforming to the WAC). When the emplaced waste volume ( $\left.309 \mathrm{~m}^{3}\right)$ is compared to the $1503 \mathrm{~m}^{3}$ assumed in the SAR and the actual percentages repackaged (100\% for LANL and RFETS residues and $0 \%$ for graphite wastes) the probability becomes $6.8 \times 10^{7}$ per year. This accident would be considered less than extremely unlikely by DOE (because it is less than $1 \times 10^{-6}$ per year) and not evaluated. The scenario was retained for conservatism and because the probability was reasonably close to $1 \times 10^{-6}$ per year.

\subsubsection{VOC Release and Risk}

The SAR assumed that all of the headspace gas in a waste container would be released instantaneously. For computational purposes in this report the release period was assumed to be one minute. The fire was assumed to occur in a LANL SWB with average VOC and radionuclide concentrations. A LANL SWB was chosen because it has the highest carcinogenic VOC concentrations and the largest amount of headspace gas volume. Since the radionuclide quantities in the RFETS residue drums are 4.5 times greater than in the LANL SWBs, these calculations maximize VOC risks rather than radionuclide risks. 
Lifetime fatal cancer risks from VOC releases are calculated in Appendix B. The risk to the surface worker is $1.9 \times 10^{-15}$ and the risk to the MIR is $1.8 \times 10^{-17}$. Note that all the accident risk values are really the risks that result if the accident occurs. The overall annual risk is much less because it is the product of the annual probability of occurrence and the risk if the accident occurs.

\subsubsection{Radionuclide Release and Risk}

The assumptions of the SAR on fractional releases from the SWB were used. The radionuclide release from $4.24 \mathrm{Ci}$ and an overall release fraction of $5 \times 10^{-4}$ is $2.12 \times 10^{-3} \mathrm{Ci}$. Calculations for releases, doses, and cancer risks are in Appendix B.

Doses and risks to the surface worker from this scenario were $28 \mathrm{mrem}$ and $2.8 \times 10^{-6}$. An underground worker would receive a dose of $17 \mathrm{rem}$ and incur a risk of $17 \times 10^{-3}$. For the MIR the doses and risks are $0.27 \mathrm{mrem}$ and $2.7 \times 10^{-8}$. A member of the public at the exclusive use area boundary would receive a dose of $1.7 \mathrm{mrem}$ and incur a risk of $1.7 \times 10^{-7}$. There are no VOC risk limits in the Permit or radionuclide risk limits for accidents.

VOC and radionuclide risks are shown in Table 4-1. 
Table 4-1. Radionuclide and VOC Carcinogenic Risks from Spontaneous Fire Scenario ${ }^{\mathrm{a}}$

\begin{tabular}{|c|c|c|c|}
\hline Source & Surface Worker & $\begin{array}{l}\text { Site Boundary } \\
\text { Resident }\end{array}$ & $\begin{array}{c}\text { Exclusive Use } \\
\text { Boundary } \\
\text { Resident }\end{array}$ \\
\hline \multicolumn{4}{|l|}{ VOC } \\
\hline Concentration $\left(\mathrm{ug} / \mathrm{m}^{3}\right)^{\mathrm{b}}$ & $1.2 \times 10^{-2}$ & $1.2 \times 10^{-4}$ & $7.3 \times 10^{-4}$ \\
\hline Risk & $1.9 \times 10^{-15}$ & $1.8 \times 10^{-17}$ & $1.1 \times 10^{-16}$ \\
\hline \multicolumn{4}{|l|}{ Radionuclide } \\
\hline Dose (mrem/y) & 28. & 0.27 & 1.7 \\
\hline Risk & $2.8 \times 10^{-6}$ & $2.7 \times 10^{-8}$ & $1.7 \times 10^{-7}$ \\
\hline Total Risk & $2.8 \times 10^{-6}$ & $2.7 \times 10^{-8}$ & $1.7 \times 10^{-7}$ \\
\hline Radionuclide/VOC Ratio & $1.5 \times 10^{9}$ & $1.5 \times 10^{9}$ & $1.5 \times 10^{9}$ \\
\hline
\end{tabular}

${ }^{a}$ Risks assume the probability of the scenario is 1.0

${ }^{b}$ Combined concentration for both VOCs

\subsection{Roof Fall Scenario}

\subsubsection{Scenario Description}

The SAR roof fall scenario was patterned after the roof fall that occurred in the experimental area of the repository in Site Preliminary Design Validation Room 1 in 1991. This roof fall was in the shape of an elongated pyramid, approximately 33 feet wide by seven feet high by 180 feet long, and weighed about 700 tons. The scenario was assumed to occur in an active disposal room where waste containers are still being emplaced. Falling salt knocks seven SWBs off the top stack and five of these are breached. All (100\%) of the VOC headspace gas is released from these five SWBs. The aerosolized and respirable radionuclide release is $1.0 \times 10^{-5}$ of the contents of a SWB. For five SWBs with $4.24 \mathrm{Cj} / \mathrm{SWB}$ this results in a source term of $2.12 \times 10^{-4} \mathrm{Ci}$. Released material is transported in room ventilation air to the surface. 


\subsubsection{Scenario Probability}

The SAR developed a rationale and fault tree to arrive at an annual probability of $4.7 \times 10^{-7}$ that an unexpected roof fall will occur in an unisolated (open) waste room. This scenario would not have to be evaluated according to DOE procedures because the probability is $<1 \times 10^{-6} / \mathrm{y}$. Several factors combine to create this low probability value, and a major factor is the belief that there are enough signs in the days or weeks leading up to a roof fall that an imminent fall would almost certainly be detected beforehand.

Emphasis is placed in the SAR analyses on an unexpected roof fall because of the belief that, even with a few minute warning, the area could be evacuated and ventilation exhaust switched to filtration. With a few days warning the affected area could be isolated with emergency barriers and emplacement operations elsewhere be abandoned if necessary .

There are several reasons why preparation for an imminent roof fall may not be as simple and effective as described in the SAR. For example, the DOE may be reluctant to: (1) put workers in the downstream ventilation path to install a ventilation barrier; (2) stop all waste emplacement operations in the affected and adjacent rooms for many days; and (3) operate in the filtration mode for long periods of time (which also precludes waste emplacement). Also, if the fall were to occur in the off-shift, there would be no two minute warning to activate a switch to filtration before a release. Therefore, EEG believes that even if there are signs of an imminent roof fall, the timing of mitigative measures may not ensure complete containment of a release.

\subsubsection{EEG Views on Roof Fall Probability in Panel 1.}

Panel 1 room stability has been a cause of concern for many years, and the SAR recognized that Panel 1 is more susceptible to roof fall. The basic problem is the length of time the rooms have been open. Mining of the panel began in May 1986 and was completed in June 1988. This schedule was to accommodate the anticipated first receipt of wastes in 1988. Concern arose about the useful lifetime of these rooms when the schedule slipped and it became apparent the 
panel would not be filled with waste for many years. A group of geotechnical experts was assembled by DOE in April 1991 to provide advice on the useful life span of Panel 1 and recommend remedial measures (US DOE 1991). The group concluded that the rooms would remain stable without additional support with high confidence until 1993 and with decreasing confidence until 1997. All of the rooms in Panel 1 were fitted with three meter roof bolts in the 1988-89 period. Additional support systems have been installed in portions of Panel 1 since 1989. Room 7, which is our primary concern in this evaluation, completed a tertiary support system in May 1998.

EEG retained a mining engineer, Hamid Maleki, as a consultant in 1996 and in 1998 to evaluate the stability of Panel 1. Dr. Maleki had previously evaluated WIPP mine safety for the U.S. Bureau of Mines in 1993, 1994, and 1995. Dr. Maleki concluded after his 1996 evaluation (Maleki and Chaturvedi 1996) that there were remedial steps that could be taken to enhance stability during emplacement operations. However, he also said, “To 'assure stability' and safety, it is best to abandon Panel 1 and mine a new panel as soon as all permitting processes are complete". In his 1998 report Dr. Maleki stated "Time of roof collapse cannot be estimated with a high degree of confidence if internal tertiary support systems are used without external support systems, such as cribs. The potential for roof falls is expected to be low within the first year and increase significantly in some locations approximately 2 years after installation of tertiary support" (Maleki 1998).

Because of the concerns expressed by others and our own evaluations, EEG has recommended that DOE certify each room in Panel 1 before waste emplacement operations begin. At design emplacement rates a room would be filled in about six months and the one to two year stability period predicted by Maleki would be more than adequate. On July 21, 1999, Westinghouse cleared Room 7 for waste emplacement operations until June 30, 2000 (Patchet 1999). However, because of the slow emplacement rate the room will not be filled until late in the year 2000 or early in 2001. Inspections and remedial measures in the portion of Room 7 already filled with waste will be difficult because of access problems. 
For the above reasons EEG believes a roof fall in Room 7 has a probability much greater than $1 \times 10^{-6} / \mathrm{y}$, and the scenario needs to be evaluated.

\subsubsection{VOC Release and Risk}

Since $100 \%$ of the headspace gas is assumed to be released from each of the five SWBs breached in the roof fall scenario, the release and the risks from this accident would be five times as great as in the underground (UG) fire scenario. The risks are $9.3 \times 10^{-15}$ for the surface worker and $9.1 \times 10^{-17}$ for the public member at the WIPP Site Boundary.

\subsubsection{Radionuclide Release and Risk}

The SAR assumed radionuclide release from the roof fall scenario to be $10 \%$ of the release from the UG fire scenario. This lower release occurs because the roof fall damage ratio is $1 \%$, the airborne release factor is two times and the material at risk is five times that in the UG fire scenario. The calculated radionuclide risks are $1.7 \times 10^{-4}$ for the UG worker, $2.8 \times 10^{-7}$ for the surface worker, $2.1 \times 10^{-9}$ for the MIR, and $1.7 \times 10^{-8}$ for a public member at the northern exclusive use area boundary.

\subsection{Radionuclide to VOC Risks}

The risk from radionuclide releases is $1.5 \times 10^{9}$ times the VOC release for the UG fire scenario. In the roof fall scenario the radionuclide risk is $3.0 \times 10^{7}$ times the VOC risk. So, the risk from VOC releases is negligible compared to that from radionuclide releases.

The radionuclide risk to a surface worker from the UG fire scenario accident is greater than $1 \times 10^{-6}$. This is very small, but not negligible. However, the overall annual risk would be much smaller because this is an unlikely accident. 


\section{CONCLUSIONS \& RECOMMENDATIONS}

\subsection{Conclusions}

The WAP requirements for waste characterization are often more prescriptive than the QAPP requirements used for pre-Permit characterization, but the essence of the technical requirements appears to be similar.

Deviations granted by DOE during pre-Permit waste characterization and the premature closure of some corrective actions required by independent audits may result in the most significant differences in waste characterization.

Estimated carcinogenic risks to a surface worker and member of the public from routine operations involving TRU wastes emplaced in Panel 1, Room 7 during 1999 are seven to eight orders of magnitude less than allowed by the Permit and five to six orders of magnitude less than expected from the entire WIPP Project over 35 years. Non-carcinogenic risks are nine to ten orders of magnitude below the allowed limit and two to four orders of magnitude below expected risks for the repository.

Estimated carcinogenic risk to the underground worker from routine operations are six orders of magnitude below the allowable risk level for surface workers. Non-carcinogenic risks are seven orders of magnitude below a hazard level.

Even if VOC emissions are much higher than expected, the Confirmatory VOC Monitoring Plan at WIPP would detect concentrations that are three orders of magnitude below allowable Permit limits. Any hazardous emissions from pre-Permit wastes would likely be reported and acted on long before Permit limits were reached. 
Risks from low probability accidents are within an order of magnitude of the allowable Permit limits from routine emissions of VOCs. These risks are essentially all from inhalation of released radionuclides with the radiation/VOC risk ratio being $23 \times 10^{7}$.

Radiation doses and risks to an underground worker for the spontaneous fire scenario are significant ( $17 \mathrm{rem}$ and $1.7 \times 10^{-3}$ risk). Doses from the roof fall scenario are one-tenth of those from the spontaneous fire scenario.

\subsection{Recommendations}

The data for the individual container lots of pre-Permit waste can be reviewed for being "characterized in accordance with the WAP," if this becomes necessary. This determination by NMED should consider all deviations and include input from the DOE.

The estimated non-accidental risks from the presently stored waste in Room 7 are so low that they should not be used as a justification for any remedial or other actions involving these wastes.

Radionuclide risks to underground workers from low probability spontaneous fire and roof fall accidents should be considered when setting restrictions on worker access to the south 1600 and east 300 drifts. 


\section{REFERENCES}

Brown, Michael R., 1999a. Memorandum from U. S. Department of Energy, Carlsbad Area Office, to Eric Pennala, Mobile Characterization Services, January 12, 1999, on MCS HGAS Sampling Equivalency. CAO:OWDO:MRB 99-0315.

Brown, Michael R., 1999b. Memorandum from U. S. Department of Energy, Carlsbad Area Office, to Joseph Legare, U. S. Department of Energy, Rocky Flats Area Office, February 25, 1999, on Clarification of Requirements in the QAPP, Revision 0, Interim Change. CAO:OWDO:MRB 99-0358.

Channell, James K. and Robert H. Neill, 1999. A Comparison of the Risks from the Hazardous Waste and Radioactive Waste Portions of the WIPP Inventory. New Mexico Environmental Evaluation Group. EEG-72. July 1999.

Hunter, E. Kent, 1998a. Memorandum from U. S. Department of Energy, Carlsbad Area Office, to Joseph Legare, U. S. Department of Energy, Rocky Flats Field Office, February 12, 1998, on Residue TRU Waste Characterization Methods Evaluation. CAO:NTP:RAS 980617.

Hunter, E. Kent, 1998b. Letter from U. S. Department of Energy, Carlsbad Area Office, to Bruce LeBrun, U. S. Department of Energy, Los Alamos Area Office, July 8, 1998, on Testing Requirements for Repackaged Waste.

Hunter, E. Kent, 1998c. Memorandum from U. S. Department of Energy, Carlsbad Area Office, to Joseph A. Legare, U. S. Department of Energy, Rocky Flats Field Office, July 14, 1998, on RFFO Exemption Request for Preserving Samples of Salt Waste. CAO:QA:RAS 98-0958.

Hunter, E. Kent, 1998d. Memorandum from U. S. Department of Energy, Carlsbad Area Office, to Joe Legare, U. S. Department of Energy, Rocky Flats Area Office, August 21, 1998, on Request for an Equivalency Determination for Sampling Residue Salts. CAO:OWDO:BS 98-1407.

Hunter, E. Kent, 1998e. Memorandum from U. S. Department of Energy, Carlsbad Area Office, to Joseph Legare, U. S. Department of Energy, Rocky Flats Area Office, August 26, 1998, on Equivalency Request for Ash Sampling Method. CAO:QA:RAS 98-1509 UFC 5822.

Hunter, E. Kent, 1998f. Memorandum from U. S. Department of Energy, Carlsbad Area Office, to Joseph A. Legare, U. S. Department of Energy, Rocky Flats Field Office, September 29, 1998, on Response to RFETS Letter AMEC:ERWM:LNX:03803. CAO:OWDO:RAS 98-1424. 
Hunter, E. Kent, 1998g. Memorandum from U. S. Department of Energy, Carlsbad Area Office, to Joseph Legare, U. S. Department of Energy, Rocky Flats Field Office, October 9, 1998, on RFETS Request to Reduce the 72-hr Equilibration Time Requirement. CAO:NTP:RAS 98-1434.

Kirkpatrick, T. D., 1995. DOE Waste Treatability Group Guidance. U. S. Department of Energy, Idaho National Engineering Laboratory, Lockheed Idaho Technologies Company. DOE/LLW-217, Rev. 0. January 1995.

Maleki, Hamid, and Lokesh Chaturvedi, 1996. Stability Evaluation of the Panel 1 Rooms and the E140 Drift at WIPP. Environmental Evaluation Group. EEG-63. August 1996.

Maleki, Hamid, 1998. Mine Stability Evaluation of Panel 1 During Waste Emplacement Operations at WIPP. Environmental Evaluation Group. EEG-71. July 1998.

National Academy of Sciences, 1988. Health Risks of Radon and Other Internally Deposited Alpha-Emitters, BEIR IV. National Research Council, Board on Radiation Effects Research Commission on Life Sciences, Committee on the Biological Effects of Ionizing Radiation.

New Mexico Environment Department, 1999a. Intent to Issue a Permit for the Operation of a Hazardous Waste Storage and Disposal Facility Under the New Mexico Hazardous Waste Act, Waste Isolation Pilot Plant, Carlsbad, New Mexico. Supplemental Fact Sheet, EPA No. NM4890139088. January 14, 1999.

New Mexico Environment Department, 1999b. Hazardous Waste Final Permit: Issued to Waste Isolation Pilot Plant. EPA No. NM4890139088. November 26, 1999.

New Mexico Hazardous Waste Act, 1978. NMSA 1978, sect. 74-4-1 through 74-4-14 (Repl. Pamp. 1993).

Patchet, Stanley J., 1999. Memorandum from Westinghouse Waste Isolation Division to D. P. Reber, Westinghouse Waste Isolation Division, July 21, 1999. HA:99:02053, UFC: 6500.00 .

Resource Conservation and Recovery Act, 1976. (42 U.S. Code s/s 6901 et seq.).

Rogers, Pamela, 1999. Telephone conversation, Rogers, Los Alamos National Laboratory, and James K. Channell, Environmental Evaluation Group, October 18, 1999

Stroud, Robert A., 1998. Memorandum from U. S. Department of Energy, Carlsbad Area Office, to Bruce LeBrun, U. S. Department of Energy, Los Alamos Area Office, May 8, 1998, on RTR Guidance. CAO:ORCA:RAS 98-0391. 
U. S. Department of Energy, 1991. Report of the Geotechnical Panel on the Effective Life of Rooms in Panel 1. DOE/WIPP 91-023.

U. S. Department of Energy, 1995a. Performance Demonstration Program Plan for Analysis of Simulated Headspace Gases. Carlsbad Area Office. DOE/CAO-95-1076, Rev. 0. June 1995.

U. S. Department of Energy, 1995b. Performance Demonstration Program Plan for RCRA Constituent Analysis of Solidified Wastes. Carlsbad Area Office. DOE/CAO-95-1077, Rev. 0. June 1995.

U. S. Department of Energy, 1996a. Performance Demonstration Program Plan for RCRA Constituent Analysis of Solidified Wastes. Carlsbad Area Office. DOE/CAO-95-1077, Rev. 1. March 1996.

U. S. Department of Energy, 1996b. Quality Assurance Program Document. Carlsbad Area Office. CAO-94-1012, Rev. 1. April 1996.

U. S. Department of Energy, 1996c. Transuranic Waste Characterization Sampling and Analysis Methods Manual. Carlsbad Area Office. DOE/WIPP-91-043, Rev. 1.0. April 1996.

U. S. Department of Energy, 1996d. Transuranic Waste Characterization Quality Assurance Program Plan. Carlsbad Area Office. CAO-94-1010, Rev. 0. November 15, 1996 (includes February 1996 interim change).

U. S. Department of Energy, 1997. Resource Conservation and Recovery Act Part B Permit Application. Waste Isolation Pilot Plant. DOE/WIPP 91-005, Rev. 6.

U. S. Department of Energy, 1998a. Final Environmental Impact Statement on Management of Certain Plutonium Residues and Scrub Alloy Stored at the Rocky Flats Environmental Technology Site. Center for Environmental Management. DOE/EIS-0277F. August 1998.

U. S. Department of Energy, 1998b. Quality Assurance Program Document. Carlsbad Area Office. CAO-94-1012, Rev. 2. September 1998.

U. S. Department of Energy, 1999a. Waste Isolation Pilot Plant Safety Analysis Report. DOE/WIPP-95-2065, Rev. 3. January 1999.

U. S. Department of Energy, 1999b. Performance Demonstration Program Plan for Analysis of Simulated Headspace Gases. Carlsbad Area Office. DOE/CAO-95-1076, Rev. 1. April 1999. 
U. S. Department of Energy, 1999c. Performance Demonstration Program Plan for RCRA Constituent Analysis of Solidified Wastes. Carlsbad Area Office. DOE/CAO-95-1077, Rev. 2. April 14, 1999.

U. S. Department of Energy, 1999d. Corrective Action Report, Carlsbad Area Office, CAR No. 99-068, Audit A-9908, Block 9, chain-of-custody adequacy. June 2, 1999.

U. S. Department of Energy, 1999e. Corrective Action Report, Carlsbad Area Office, CAR No. 99-069, Audit A-99-08. June 2, 1999.

U. S. Department of Energy, 1999f. Quality Assurance Program Document. Carlsbad Area Office. CAO-94-1012, Rev. 3. November 1999.

U.S. Department of Energy, 1999g. Waste Acceptance Criteria for the Waste isolation Pilot Plant. Carlsbad Area Office. DOE/WIPP-069, Rev. 7. November 26, 1999.

U. S. Environmental Protection Agency, 1988. Limiting Values of Radionuclide Intake and Air Concentrations and Dose Conversion Factors for Inhalation, Submersion, and Ingestion. Federal Guidance Report No. 11. EPA 520/1-88-020. September 1988.

U. S. Environmental Protection Agency, 1996. Test Methods for Evaluating Solid Waste, Physical/Chemical Methods, SW-846. EPA/SWA-846. December 1996.

U. S. Environmental Protection Agency, 1997. Environmental Radiation Protection Standards for Management and Disposal of Spent Nuclear Fuel, High-Level and Transuranic Radioactive Wastes. U. S. Code of Federal Regulations. 40 CFR Part 191. July 1, 1997.

U. S. Nuclear Regulatory Commission, 1983. Atmospheric Dispersion Models for Potential Accident Consequence Assessments at Nuclear Power Plants. Regulatory Guide 1.145, Revision 1. February 1983.

Vega, Samuel A., 2000. Memorandum from U. S. Department of Energy, Carlsbad Area Office, to G. Streier, TRUtech, T. Krause, TRUtech, E. Pennela, MCS, L. Fritz, DOE-ID, T. Monk, INEEL, P. Rogers, LANL, M. Gavett, LANL, C. Murnane, DOE/LAAO, January 18, 2000, on Closure of CARs Citing QAPP or Method Manual Requirements. CAO:PQA:SAV:00-0209 UFC 2300.

Watkins, Don, 1997. Memorandum from U. S. Department of Energy, Carlsbad Area Office, to Jerry Wells, U. S. Department of Energy, Idaho, August 29, 1997, on Guidance for Retrieval of Drums. CAO:NTP:RAS 97-1847 UFC 5822.

Westinghouse Government Environmental Service Company, Waste Isolation Division, 1999. Waste Isolation Pilot Plant 1998 Site Environmental Report. Prepared for U. S.

Department of Energy, ed. Balwan S. Hooda and Vivian L. Allen. DOE/WIPP 99-2225. October 1999. 


\section{APPENDICES}




\section{APPENDIX A \\ CALCULATION OF RISK ANALYSIS FOR ROUTINE OPERATIONS}

\section{A.1 Development of VOC Source Term}

\section{A.1.1 Available Data}

Data used in risk analysis calculations was taken from the WIPP Waste Information System (WWIS). Head Space Gas (HSG) analyses were available for all LANL Standard Waste Boxes (SWBs), all INEEL drums, and for the 26 RFETS graphite waste drums. There were no data for the 408 residue drums from RFETS.

The LANL HSG measurements were taken from the parent drums of heat source waste. Subsequent to the HSG analyses each parent drum was divided into several daughter drums so that the curie content would be low enough to ship in the TRUPACT-II package. Each of the daughter drums was placed into a SWB without its drum lid and with three empty drums. LANL took the measured VOC concentrations in each parent drum and assigned the full value to each of that drum's daughter drums. This same HSG concentration was assumed to be the HSG concentration in the SWB. (Rogers 1999). This is undoubtedly a conservative assumption, but the amount of conservatism is unknown. The values assigned by LANL were used in this report.

No corrections were made for the HSG concentrations for the graphite waste stream drums from INEEL (120 drums) and RFETS (26 drums).

The RFETS residues are pyro-oxidized salts that have been heat treated at sufficiently high temperatures to drive off any VOCs present. This was the basis for the DOE Carlsbad Area Office to grant RFETS an exemption from HSG Sampling (Hunter 1998a) The WAP requires all containers to have HSG sampling and contains no procedure for granting exemptions. 
A lack of $\mathrm{HSG}$ data for the residues creates an uncertainty in this risk analysis. Although the argument that the pyro-oxidation process would drive off all VOCs is reasonable, it should be noted that the LANL wastes, which have been shown to be non-RCRA wastes, contain detectable amounts of VOCs in about one-half of the SWBs. This risk analyses assumes that the residues contain the same HSG concentration as the 26 drums of RFETS graphite wastes. This is probably a conservative assumption but there is uncertainty.

\section{A.1.2 Selection of VOCs}

Approximately 25 VOCs were analyzed by the generator sites. The proposed NMED Permit requires room based concentration limits for only nine of these VOCs which contain about $99 \%$ of the expected total carcinogenic and non-carcinogenic risk. This risk screening was based on a combination of the projected weighted average concentrations in the repository and the risk coefficients for the individual VOCs.

EEG's screening for this risk analysis considered the nine VOCs included in the Permit, as well as those VOCs that were frequently detected and had average concentrations $\geq 1 \mathrm{ppmv}$ at one or more of the generator sites.

Reported VOC concentrations are low in all cases, as would be expected for wastes shipped as non-RCRA wastes. Most VOC measurements are less than the minimum detectable concentration (MDC) and the value reported is the MDC with a $U$ designator. Most of the values greater than the $\mathrm{MDC}$ are less than the program required quantitation limit (PRQL) and are designated $\mathrm{J}$. The only VOCs with any values greater than the PRQL were acetone at LANL and 1,1, 1-trichloroethane, toluene ( 1 only), and carbon tetrachloride ( 1 only) at INEEL. In calculating average values, those concentrations designated $U$ were assigned one-half the reported value and $\mathrm{J}$ designated concentrations were assigned the full value.

Five of the VOCs met the screening criteria and were retained for the risk analyses. Only three of these (1,1,1-trichloroethane, methylene chloride and toluene) were among the nine VOCs for 
which environmental monitoring measurements are required by the Permit. Table A-1 includes a total of nine VOCs that had sufficient concentrations and levels of detection to warrant calculation. Acetone and methanol had the highest average concentrations and are of concern in shipping because they are flammable. However, neither are a carcinogenic or non-carcinogenic risk, and are not included in the risk analysis.

The weighted average value per container was determined by weighing the average concentration from each site by its fraction of the total containers employed in WIPP as of October 26, 1999, (101 SWBs from LANL, 126 drums from INEEL, and 434 drums from RFETS). LANL SWBs were counted as two drum equivalents because they contain two filters and $>6$ times the head space gas volume of a drum. The fractions of total drum equivalents is 0.265 for LANL, 0.165 from INEEL, and 0.570 for RFETS.

Table A-1. VOC Concentrations in Pre-Permit Waste at WIPP

\begin{tabular}{|c|c|c|c|c|c|}
\hline \multirow[b]{2}{*}{ VOC } & \multicolumn{3}{|c|}{ Average Concentrations - ppmv } & \multirow{2}{*}{$\begin{array}{c}\text { Weighted } \\
\text { Average } \\
\text { (ppmv) }\end{array}$} & \multirow[b]{2}{*}{ Comments } \\
\hline & LANL & RFETS & INEEL & & \\
\hline Acetone & 60.2 & 4.6 & 5.9 & 19.6 & delete, not HW Risk \\
\hline Methanol & 22.1 & 9.1 & 6.8 & 12.2 & delete, not HW Risk \\
\hline 1,1,1-Trichloroethane & 1.0 & 0.1 & 15.9 & 2.9 & non-carcinogen \\
\hline Methylene Chloride & 1.0 & 0.09 & 0.54 & 0.41 & carcinogen \\
\hline Methyl Ethyl Ketone & 16.1 & 0.37 & 0.47 & 4.6 & non-carcinogen \\
\hline Toluene & 1.9 & 0.28 & 0.17 & 0.69 & non-carcinogen \\
\hline Carbon Tetrachloride & 0.9 & 0.1 & 0.4 & 0.37 & delete, few $\mathrm{J}$ values \\
\hline Benzene & 1.1 & 0.14 & 0.12 & 0.39 & carcinogen \\
\hline Trichloroethylene & 0.9 & 0.00 & 0.2 & 0.27 & delete, no J values \\
\hline
\end{tabular}




\section{A.2 Exhaust Shaft and Environmental Concentrations}

The weighted VOC concentration for each VOC from Table A-1 can be related to the exhaust

shaft concentration (ECS) by the following expression (from Appendix D9 of the Application):

$$
E C S=x \frac{\left[\mathrm{D}_{\mathrm{voc}}(\mathrm{MF})_{\mathrm{voc}}\right] \mathrm{MW}_{\mathrm{voc}}\left(1 \times 10^{6} \mu \mathrm{g} / \mathrm{g}\right)}{\mathrm{V}(.0283) \mathrm{m}^{3} / \mathrm{ft}^{3}(.01667 \mathrm{~min} / \mathrm{s})}
$$

where:

$$
\begin{aligned}
& \mathrm{x} \quad=\text { number of drum equivalents, } 762 \\
& \mathrm{D}_{\mathrm{voc}}=\text { diffusion rate through an NFT-013 filter, moles/s-mole fraction-drum } \\
& \mathrm{MW}_{\mathrm{voc}}=\text { molecular weight of VOC, grams per mole } \\
& \mathrm{MF}_{\mathrm{voc}}=\text { mole fraction mole/mole } \\
& \mathrm{V} \quad=\text { exhaust ventilation rate, }(260,000) \text { cubic feet per minute }
\end{aligned}
$$

When constant values are combined, Equation A-1 reduces to:

$$
E C S=6.21 \times 10^{6} D_{v o c} M F_{v o c}\left(M W_{v o c}\right) \mu g / m^{3}
$$

Filter specific diffusion rates for each VOC relative to $\mathrm{H}_{2}$ gas were calculated from Equation D97 in Appendix D9 of the Application. Molecular weight, critical pressure, and critical temperature of a VOC are factors in determining the diffusion rate.

Exhaust shaft concentrations are shown in Table A-2. The annual air dispersion factors (ADF) for determining VOC concentrations in the environment were taken from Appendix D9. These values are $1.23 \times 10^{-2}$ for the aboveground worker and $1.2 \times 10^{-4}$ at the WIPP site boundary. The calculated VOC concentrations at these two locations are also shown in Table A-2. 
Table A-2. VOC Concentrations in Exhaust Ventilation \& Environment From Pre-Permit Waste at WIPP

\begin{tabular}{|c|c|c|c|c|c|c|}
\hline \multirow{2}{*}{ VOC } & \multirow{2}{*}{$\begin{array}{c}D_{\text {voc }} \\
\text { Mole/s-mole } \\
\text { fraction-drum }\end{array}$} & \multirow{2}{*}{$\begin{array}{l}\text { Mole } \\
\text { Fraction }\end{array}$} & \multirow{2}{*}{$\begin{array}{c}\text { Molecular } \\
\text { wt. }\end{array}$} & \multicolumn{3}{|c|}{ Concentrations $-\mu \mathrm{g} / \mathrm{m}^{3}$} \\
\hline & & & & $\begin{array}{c}\text { Exhaust } \\
\text { Shaft }\end{array}$ & $\begin{array}{l}\text { Above } \\
\text { Ground }\end{array}$ & $\begin{array}{c}\text { Site } \\
\text { Boundary }\end{array}$ \\
\hline Methylene Chloride & $1.47 \times 10^{-6}$ & $4.1 \times 10^{-7}$ & 84.94 & $3.18 \times 10^{-4}$ & $3.91 \times 10^{-6}$ & $3.81 \times 10^{-8}$ \\
\hline Benzene & $2.06 \times 10^{-6}$ & $3.9 \times 10^{-7}$ & 78.11 & $3.89 \times 10^{-4}$ & $4.78 \times 10^{-6}$ & $4.67 \times 10^{-8}$ \\
\hline 1,1,1-Trichloroethane & $1.21 \times 10^{-6}$ & $2.9 \times 10^{-6}$ & 133.42 & $2.90 \times 10^{-3}$ & $3.57 \times 10^{-5}$ & $3.48 \times 10^{-7}$ \\
\hline Methyl Ethyl Ketone & $1.30 \times 10^{-6}$ & $4.6 \times 10^{-6}$ & 72.11 & $2.67 \times 10^{-3}$ & $3.28 \times 10^{-5}$ & $3.20 \times 10^{-3}$ \\
\hline Toluene & $1.19 \times 10^{-6}$ & $6.9 \times 10^{-7}$ & 92.13 & $4.69 \times 10^{-4}$ & $5.77 \times 10^{-6}$ & $5.63 \times 10^{-8}$ \\
\hline
\end{tabular}

\section{A.3 Risk to Surface Worker}

The surface worker is assumed to be exposed to VOC emissions from the repository exhaust ventilation shaft for a period of 1920 hours a year. This calculation also assumed Room 7 will remain open for a period of one year before being filled and sealed. Room 7 could be open less than one year if the decision is made to seal the partially filled room before bringing in RCRA regulated waste. However, it will probably be some time in the year 2001 before the room will be completely filled. Carcinogenic risks from each VOC can be determined for the surface worker by the following relationship:

$$
\text { Risk }=E C S(A D F) s(U R F) F S
$$

where:

$\mathrm{URF}=$ cancer unit risk factor (for a lifetime exposure) in $\mathrm{m}^{3} / \mu \mathrm{g}$

$(A D F) s=$ air dispersion factor for surface worker, dimensionless

$\mathrm{Fs}=$ fraction of lifetime exposed, dimensionless 
Current unit risk factors (URF) were obtained from EPA's IRIS data base. The URF is expressed in reciprocal concentration units so that the product of Equation A-3 is dimensionless. The air dispersion factor is $1.23 \times 10^{-2}$ and $\mathrm{Fs}$ is 0.00392 (1920 hours exposure in one year at $1.2 \mathrm{~m}^{3} / \mathrm{h}$ inhalation rate divided by a lifetime inhalation of $588,000 \mathrm{~m}^{3}$ ). Any exposure to carcinogens is assumed to result in a risk, regardless of the concentration (i.e., there is no threshold below which no damage occurs). The total VOC carcinogenic risk can be obtained by summing the total carcinogenic risks from all the carcinogenic VOCs.

Non-carcinogenic effects are evaluated using a hazard quotient from each $\mathrm{VOC}_{\mathrm{i}}\left(\mathrm{HQ}_{\mathrm{i}}\right)$ defined as:

$$
H Q_{i}=\frac{\text { average exposure concentration, } V O C_{i}}{R f C_{i}}(F)
$$

where:

$\mathrm{RfC}_{\mathrm{i}}=$ the chronic reference dose for exposure by inhalation from $\mathrm{VOC}_{\mathrm{i}}, \mu \mathrm{g} / \mathrm{m}^{3}$ $\mathrm{F}=$ fraction of a 35 year working lifetime exposed

Values of $\mathrm{RfC}_{\mathrm{i}}$ are obtained from the IRIS data base. In this case $\mathrm{F}$ is $0.00784\left(2340 \mathrm{~m}^{3}\right.$ inhaled in one year divided by $294,000 \mathrm{~m}^{3}$ ).

The sum of the $\mathrm{HQ}_{\mathrm{i}}$ values for all radionuclides can be summed into a Hazard Index (HI):

$$
H I=\sum_{i=1}^{i=t} H Q_{i}
$$

For $\mathrm{HI}$ values less than 1.0 adverse health effects are unlikely and, because non-carcinogens have a threshold below which damage does not occur, values much below 1.0 have no precise meaning. Long-term non-carcinogenic health effects are possible for $\mathrm{HI}$ exposures greater than 
1.0. The $\mathrm{HI}$ is definitely not probabilistic, i.e., a value of 0.01 does not imply a $1 \%$ probability of an effect.

Risks to surface workers from carcinogens and non-carcinogens are shown in Table A-3. These risks are extremely low. The implications of these values are discussed in Chapter 3.

Table A-3. Annual Risks to Surface Worker from Carcinogens and Non-Carcinogens From Pre-Permit Wastes at WIPP

\begin{tabular}{|l|c|c|c|}
\hline \multicolumn{1}{|c|}{ VOC } & $\begin{array}{c}\text { ECS(ADF)F } \\
\mu \mathrm{g} / \mathrm{m}^{3}\end{array}$ & $\begin{array}{c}\text { URF } \\
\left(\mathrm{m}^{3} / \mu \mathrm{g}\right)\end{array}$ & Risk \\
\hline \multicolumn{1}{|c|}{ Carcinogens } & & & \\
Methylene Chloride & $1.53 \times 10^{-8}$ & $4.7 \times 10^{-7}$ & $7.20 \times 10^{-15}$ \\
Benzene & $1.88 \times 10^{-8}$ & $8.3 \times 10^{-6}$ & $\frac{1.56 \times 10^{-13}}{1.63 \times 10^{-13}}$ \\
Total & & & $\underline{\mathrm{HO}}$ \\
\hline Non-Carcinogen & & $\underline{\mathrm{RfC}}$ & $4.00 \times 10^{-10}$ \\
1,1,1-Trichloroethane & $2.80 \times 10^{-7}$ & 700 & $2.57 \times 10^{-10}$ \\
Methyl Ethyl Ketone & $2.57 \times 10^{-7}$ & 1000 & $\frac{1.13 \times 10^{-10}}{7.70 \times 10^{-10}}$ \\
Toluene & $4.52 \times 10^{-8}$ & 400 & $\mathrm{HI}=7.700$ \\
Total & & &
\end{tabular}

\section{A.4 Risk at WIPP Site Boundary}

The Maximum Individual Receptor (MIR) is defined as a member of the public who resides at the WIPP site boundary. Residence time is assumed to be $100 \%$ for the year. The methodology for calculating the risk is the same as for the surface worker and the only values changed are $\operatorname{ADF}\left(1.2 \times 10^{-4}\right), F$ for carcinogens (.0143), and $\mathrm{F}$ for non-carcinogens (0.0286). The results are shown in Table A-4. 
Table A-4. Annual Risks to Member of the Public from Carcinogens and Non-Carcinogens From Pre-Permit Waste at WIPP

\begin{tabular}{|l|c|c|c|}
\hline \multicolumn{1}{|c|}{ VOC } & $\begin{array}{c}\text { ECS }(\mathrm{ADF}) \mathrm{F} \\
\left(\mu \mathrm{g} / \mathrm{m}^{3)}\right.\end{array}$ & $\begin{array}{c}\mathrm{URF} \\
\left(\mathrm{m}^{3} / \mu \mathrm{g}\right)\end{array}$ & Risk \\
\hline \multicolumn{1}{|c|}{ Carcinogens } & & & $2.56 \times 10^{-16}$ \\
Methylene Chloride & $5.45 \times 10^{-10}$ & $4.7 \times 10^{-7}$ & $\underline{5.54 \times 10^{-15}}$ \\
Benzene & $6.68 \times 10^{-10}$ & $8.3 \times 10^{-6}$ & $5.80 \times 10^{-15}$ \\
Total & & $\underline{\mathrm{RfC}}$ & $\underline{\mathrm{HQ}}$ \\
\hline Non-Carcinogen & & 700 & $1.42 \times 10^{-11}$ \\
$1,1,1$-Trichloroethane & $9.95 \times 10^{-9}$ & 1000 & $9.16 \times 10^{-12}$ \\
Methyl Ethyl Ketone & $9.16 \times 10^{-9}$ & 400 & $4.02 \times 10^{-12}$ \\
Toluene & $1.61 \times 10^{-9}$ & & $\mathrm{HI}=2.74 \times 10^{-11}$ \\
\hline
\end{tabular}

\section{A.5 Risk to Underground Workers}

Underground workers are estimated to be in the south 1600 exit panel drift for 20 minutes each time they enter to inspect and service the CAMs located at the Room 7 bulkhead. For two entries per day and 200 days per year this amounts to approximately 130 hours of exposure per year. The exit air flow from Room 7 and in the drift is assumed to be 35,000 cubic feet per minute, and the VOC emissions to be fully mixed at the location of the underground workers. The flow and mixing assumptions do not reflect actual conditions for two reasons: (1) The $35,000 \mathrm{cfm}$ flow was used during the waste emplacement period. However, during much of the time between emplacement of the last of the pre-Permit wastes prior to November 26, 1999, and about March 13, 2000, when waste emplacement resumed, the flow through Room 7 was reduced to very low levels by installation of a brattice cloth at the inlet to the room; and (2) it is likely that much of the time workers were near the bulkhead and at the location of the CAMs they were exposed to air that contained a lower concentration of VOCs than would occur once there was 
complete mixing. The first condition would result in higher VOC concentrations at the exit louvers, but probably less mixing, and could cause higher exposures than calculated for the timeperiod of low flow. Condition 2, if it exists, would decrease calculated exposures. There are no data available to quantitatively evaluate conditions 1 and 2 .

VOC concentrations in the drift can be obtained by modifying Equation A-1 to reflect the lesser dilution $(35,000 \mathrm{cpm})$ in the drift to that in the exhaust shaft $(260,000 \mathrm{cfm})$. The drift concentration is thus 7.43 times the ECS.

The carcinogenic risk to the underground worker is calculated from modifying Equation A-3. The concentration is 7.43 ECS and the ADF is 1.0. URF values are unchanged. The F value (for 130 hours at $1.2 \mathrm{~m}^{3} / \mathrm{h}$ ) is $2.65 \times 10^{-4}$.

Non-carcinogenic risks can be calculated from Equations $A-4$ and A-5. The F value (for a 35 year working lifetime) is twice the Fs value used for the carcinogenic risk $\left(5.30 \times 10^{-4}\right)$.

Carcinogenic and non-carcinogenic risks are shown in Table A-5.

Table A-5. Annual Carcinogenic and Non-Carcinogenic Risks to an Underground Worker from Pre-Permit Wastes at WIPP

\begin{tabular}{|l|c|c|}
\hline \multicolumn{1}{|c|}{ VOC } & Drift Concentration $\left(\mu \mathrm{g} / \mathrm{m}^{3}\right)$ & Risk/Hazard Quotient \\
\hline \multicolumn{1}{|c|}{ Carcinogens } & & \\
Methylene Chloride & $2.36 \times 10^{-3}$ & $2.94 \times 10^{-13}$ \\
Benzene & $2.89 \times 10^{-3}$ & $\underline{6.36 \times 10^{-12}}$ \\
Total Risk & & $6.65 \times 10^{-12}$ \\
$\quad$ & & \\
$\quad$ Non-Carcinogens & $2.15 \times 10^{-2}$ & $1.63 \times 10^{-8}$ \\
1,1,1-Trichloroethane & $1.98 \times 10^{-2}$ & $1.05 \times 10^{-8}$ \\
Methyl Ethyl Ketone & $3.48 \times 10^{-3}$ & $\underline{4.61 \times 10^{-9}}$ \\
Toluene & & $3.14 \times 10^{-8}$ \\
Hazard Index & & \\
\hline
\end{tabular}




\section{APPENDIX B \\ RISK ANALYSIS FROM ACCIDENTS}

The calculation of exposures, doses, and risks from VOC and radionuclide releases is similar for both the spontaneous underground fire and the roof fall scenarios.

\section{B.1 VOC Risks}

The ECS for accidental releases can be determined by an expression similar to expression (A-1) in Appendix A. The difference is due to replacement of the diffusion term from multiple drums by the fraction of a mole of HSG released in one minute. The ECS term becomes:

$$
(E C S)_{a c c}=5570\left(m^{3} H S G\right)(M W)(M F) \frac{\mu g}{m^{3}}
$$

The WWIS lists an average LANL standard waste box fill volume of $44 \%$. This results in a headspace gas volume of $1.064 \mathrm{~m}^{3}$ for the $1.9 \mathrm{~m}^{3} \mathrm{SWB}$. For the underground fire accident equation B-1 becomes:

$$
(E C S)_{a c c}=5930(M W)(M F) \frac{\mu g}{m^{3}}
$$

The risk to a surface worker for a one minute exposure is calculated from Equation A-3 when using an Fs value of $3.40 \times 10^{-8}$. The risk at the WIPP site boundary is obtained from using an $\mathrm{ADF}$ of $1.2 \times 10^{-4}$ and the $3.40 \times 10^{-8} \mathrm{Fs}$ value.

Results of the VOC carcinogenic risk calculation to a surface worker from the underground fire scenario are presented is Table B-1. 
Table B-1. VOC Lifetime Fatal Cancer Risk to a Surface Worker from an Underground Fire Scenario at WIPP ${ }^{\mathrm{a}}$

\begin{tabular}{|c|c|c|c|c|c|}
\hline \multirow[t]{2}{*}{ VOC } & \multirow{2}{*}{$\begin{array}{c}\text { Molecular } \\
\text { wt. }\end{array}$} & \multirow{2}{*}{$\begin{array}{l}\text { Mole } \\
\text { Fraction }\end{array}$} & \multirow{2}{*}{$\begin{array}{l}\text { URF } \\
\mathrm{m}^{3} \mu \mathrm{g}\end{array}$} & \multicolumn{2}{|c|}{ Risk } \\
\hline & & & & Surface W & S. Boundary \\
\hline Methylene Chloride & 84.94 & $1.0 \times 10^{-6}$ & $4.7 \times 10^{-7}$ & $9.90 \times 10^{-17}$ & $9.67 \times 10^{-19}$ \\
\hline Benzene & 78.11 & $1.1 \times 10^{-6}$ & $8.3 \times 10^{-6}$ & $1.77 \times 10^{-15}$ & $1.73 \times 10^{-17}$ \\
\hline \multicolumn{4}{|c|}{ Total } & $1.87 \times 10^{-15}$ & $1.83 \times 10^{-17}$ \\
\hline
\end{tabular}

${ }^{\mathrm{a}}$ Risks assume the probability of the scenarios is 1.0 .

The release from the roof fall accident is five times that from the spontaneous underground fire accident because five SWBs are breached. Therefore, the VOC carcinogenic risk would be $9.35 \times 10^{-15}$ for the surface worker and $9.15 \times 10^{-17}$ for the public member at the WIPP site boundary.

\section{B.2 Radionuclide Risk}

\section{B.2.1 Radionuclide Source Term}

The expression used in the SAR (Section 5.2.1) for determining the quantity of radioactivity (Q in curies) released is:

$$
Q=\operatorname{MAR}(D R)(A R F)(R F)(L F)
$$

where:

MAR = Material at Risk in Curies. Contents of one SWB (4.24 Ci) for underground fire and 5 SWB (21.2 Ci) for roof fall

$\mathrm{DR}=$ Damage Ratio, 1.0 for UG fire, 0.010 for roof fall

$\mathrm{ARF}=$ Airborne Release Factor, $5 \times 10^{-4}$ for UG fire, $1 \times 10^{-3}$ for roof fall.

$\mathrm{RF}=$ Respirable Fraction, 1.0 for both scenarios

LF = Leakpath Fraction, 1.0 for both scenarios 
With these assumed parameter values the radionuclide releases $(\mathrm{Q})$ are $2.12 \times 10^{-3} \mathrm{Ci}$ for the UG fire and $2.12 \times 10^{-4} \mathrm{Ci}$ for the roof fall. The roof fall values are less because the DR value for a roof fall is less than for the UG fire.

\section{B.2.2 Radionuclide Cancer Risk}

The radionuclide quantity inhaled by the surface worker or the MIR can be obtained with an expression similar to A-3. Then, multiplication by the dose conversion factor (DCF rem/Ci inhaled) and the cancer risk to dose factor (RDF) (cancer risk per rem) give the cancer risk for the radionuclide release. The risk becomes:

$$
\text { Risk }=\frac{Q(A D F)\left(1.2 \frac{\mathrm{m}^{3}}{\mathrm{hr}} \text { inhaled }\right)(D C F)(R D F)}{2.6 \times 10^{5} \frac{\mathrm{ft}^{3}}{\mathrm{~min}}\left(.0283 \frac{\mathrm{m}^{3}}{\mathrm{ft}^{3}}\right) 60 \frac{\mathrm{min}}{\mathrm{hr}}}
$$

where:

$\mathrm{ADF}=$ Air Dispersion Factor, $1.23 \times 10^{-2}$ for surface worker, $1.2 \times 10^{-4}$ for boundary

$\mathrm{DCF}=3.92 \times 10^{8}$ rem per $\mathrm{Ci}$ for ${ }^{238} \mathrm{Pu}$ (US EPA 1988)

$\mathrm{RDF}=1 \times 10^{-4}$ risk per rem (NAS 1988)

The resulting cancer risks for the UG fire scenario are $2.78 \times 10^{-6}$ for the surface worker and $2.71 \times 10^{-8}$ for the resident at the site boundary. For the roof fall scenario the risks are $2.78 \times 10^{-7}$ for the surface worker and $2.71 \times 10^{-9}$ for the MIR. Risks to the underground worker would be $1.69 \times 10^{-3}$ from the UG fire scenario and $1.69 \times 10^{-4}$ for the roof fall scenario.

A member of the public could be at the exclusive use area boundary and be exposed to the accidental release. The maximum $\mathrm{ADF}$ value shown in Appendix D9 is $7.5 \times 10^{-4}$ at the northern exclusive use area boundary. Resulting risk to a member of the public would be $1.69 \times 10^{-7}$ for the UG fire scenario and $1.69 \times 10^{-8}$ for the roof fall scenario. 


\section{B.3 Radiation to VOC Risk Ratio}

The relative risk from VOC releases compared to radionuclide releases can be obtained from the above calculations. The radionuclide risk is $1.49 \times 10^{9}$ times the VOC risk for the underground fire scenario and it is $2.97 \times 10^{7}$ times the VOC risk for the roof fall scenario.

\section{B.4 Comparison with SAR Exposures}

The values for exposure from radionuclides and VOCs in Appendix E, Revision 3 of the Safety Analysis Report are much higher than the values calculated here. There are several reasons for this:

1. The SAR used an $80 \mathrm{PE}-\mathrm{Ci}$ quantity in the container compared to the use here of the average value in the LANL SWBs $(4.24 \mathrm{Ci})$.

2. The radionuclide dose conversion factor used in the SAR was $5.1 \times 10^{8} \mathrm{rem} / \mathrm{Ci}$ for ${ }^{239} \mathrm{Pu}$ rather than the EPA value of $3.92 \times 10^{8} \mathrm{rem} / \mathrm{Ci}$ for ${ }^{238} \mathrm{Pu}$.

3. SAR radionuclide dispersion values were obtained using the $\chi / Q$ methodology and this report used the Long-Term Version of the Industrial Source Complex (ISCLT3) model (EPA) that resulted in the Appendix D9 Air Dispersion Factors. The SAR methodology resulted in concentrations about 50 times greater than the $\mathrm{ADFs}$.

Agreement with the SAR values was within one percent when these differences are incorporated.

The radionuclide dispersion calculations require greater discussion. Use of the ADF methodology, which uses annual average dispersion values, would not be conservative for the low probability one-hour conditions that might occur during an accident. The $\chi / \mathrm{Q}$ methodology calculates the dispersion of particles, atoms, or molecules and does not consider dilution prior to exhaust from the ventilation shaft. The unfiltered exhaust volume from WIPP varies between 
260,000 and $425,000 \mathrm{cfm}\left(123\right.$ to $\left.200 \mathrm{~m}^{3} / \mathrm{sec}\right)$. The concentration calculated from the $\chi / \mathrm{Q}$ methodology at $100 \mathrm{~m}$ is $63 \%$ of the concentration in the exhaust shaft at a $260,000 \mathrm{cfm}$ ventilation rate and $103 \%$ at a $425,000 \mathrm{cfm}$ rate. There is no apparent physical means by which concentrations would increase after leaving a stack. U. S. Nuclear Regulatory Commission Regulatory Guide 1.145 (US NRC 1983) assumptions lead to a prediction that the size of the WIPP exhaust plume would increase by a factor of about 3.7 at $100 \mathrm{~m}$ during very stable $(\mathrm{G})$ atmospheric stability conditions. For moderately stable (F) atmospheric stability the plume size would increase by a factor of about 24 .

It is concluded that the atmospheric dispersion factors used may be non-conservative by a factor of up to 5 for very stable Class $\mathrm{G}$ atmospheric conditions while the $\chi / \mathrm{Q}$ value would usually be conservative by an order of magnitude. The use of worst case meteorological condition may be appropriate in a consequence analysis for very low probability events where doses may be high enough to cause acute effects, but is not necessary for a risk calculation. 


\section{LIST OF EEG REPORTS}

EEG-1 Goad, Donna, A Compilation of Site Selection Criteria Considerations and Concerns Appearing in the Literature on the Deep Disposal of Radioactive Wastes, June 1979.

EEG-2 Review Comments on Geological Characterization Report. Waste Isolation Pilot Plant (WIPP) Site. Southeastern New Mexico SAND 78-1596. Volume I and II, December 1978.

EEG-3 Neill, Robert H., James K. Channell, Carla Wofsy, Moses A. Greenfield (eds.) Radiological Health Review of the Draft Environmental Impact Statement (DOE/EIS-0026-D) Waste Isolation Pilot Plant. U.S. Department of Energy, August 1979.

EEG-4 Little, Marshall S., Review Comments on the Report of the Steering Committee on Waste Acceptance Criteria for the Waste Isolation Pilot Plant, February 1980.

EEG-5 Channell, James K., Calculated Radiation Doses From Deposition of Material Released in Hypothetical Transportation Accidents Involving WIPP-Related Radioactive Wastes, October 1980.

EEG-6 Geotechnical Considerations for Radiological Hazard Assessment of WIPP. A Report of a Meeting Held on January 17-18, 1980, April 1980.

EEG-7 Chaturvedi, Lokesh, WIPP Site and Vicinity Geological Field Trip. A Report of a Field Trip to the Proposed Waste Isolation Pilot Plant Project in Southeastern New Mexico, June 16 to 18, 1980 , October 1980.

EEG-8 Wofsy, Carla, The Significance of Certain Rustler Aquifer Parameters for Predicting Long-Term Radiation Doses from WIPP, September 1980.

EEG-9 Spiegler, Peter, An Approach to Calculating Upper Bounds on Maximum Individual Doses From the Use of Contaminated Well Water Following a WIPP Repository Breach, September 1981.

EEG-10 Radiological Health Review of the Final Environmental Impact Statement (DOE/EIS-0026) Waste Isolation Pilot Plant, U. S. Department of Energy, January 1981.

EEG-11 Channell, James K., Calculated Radiation Doses From Radionuclides Brought to the Surface if Future Drilling Intercepts the WIPP Repository and Pressurized Brine, January 1982.

EEG-12 Little, Marshall S., Potential Release Scenario and Radiological Consequence Evaluation of Mineral Resources at WIPP, May 1982.

EEG-13 Spiegler, Peter, Analysis of the Potential Formation of a Breccia Chimney Beneath the WIPP Repository, May 1982.

EEG-14 Not published.

EEG-15 Bard, Stephen T., Estimated Radiation Doses Resulting if an Exploratory Borehole Penetrates a Pressurized Brine Reservoir Assumed to Exist Below the WIPP Repositorv Horizon - A Single Hole Scenario, March 1982.

EEG-16 Radionuclide Release, Transport and Consequence Modeling for WIPP. A Report of a Workshop Held on September 16-17.1981, February 1982.

EEG-17 Spiegler, Peter, Hydrologic Analyses of Two Brine Encounters in the Vicinity of the Waste Isolation Pilot Plant (WIPP) Site, December 1982.

EEG-18 Spiegler, Peter and Dave Updegraff, Origin of the Brines Near WIPP from the Drill Holes ERDA-6 and WIPP-12 Based on Stable Isotope Concentration of Hydrogen and Oxygen, March 1983. 


\section{LIST OF EEG REPORTS (continued)}

EEG-19 Channell, James K., Review Comments on Environmental Analysis Cost Reduction Proposals (WIPP/DOE-136) July 1982, November 1982.

EEG-20 Baca, Thomas E., An Evaluation of the Non-Radiological Environmental Problems Relating to the WIPP, February 1983.

EEG-21 Faith, Stuart, Peter Spiegler, Kenneth R. Rehfeldt, The Geochemistry of Two Pressurized Brines From the Castile Formation in the Vicinity of the Waste Isolation Pilot Plant (WIPP) Site, April 1983.

EEG-22 EEG Review Comments on the Geotechnical Reports Provided by DOE to EEG Under the Stipulated Agreement Through March 1, 1983, April 1983.

EEG-23 Neill, Robert H., James K. Channell, Lokesh Chaturvedi, Marshall S. Little, Kenneth Rehfeldt, Peter Spiegler, Evaluation of the Suitability of the WIPP Site, May 1983.

EEG-24 Neill, Robert H. and James K. Channell, Potential Problems From Shipment of High-Curie Content Contact-Handled Transuranic (CH-TRU) Waste to WIPP, August 1983.

EEG-25 Chaturvedi, Lokesh, Occurrence of Gases in the Salado Formation, March 1984.

EEG-26 Spiegler, Peter, Proposed Preoperational Environmental Monitoring Program for WIPP, November 1984.

EEG-27 Rehfeldt, Kenneth, Sensitivity Analysis of Solute Transport in Fractures and Determination of Anisotropy Within the Culebra Dolomite, September 1984.

EEG-28 Knowles, H. B., Radiation Shielding in the Hot Cell Facility at the Waste Isolation Pilot Plant: A Review, November 1984.

EEG-29 Little, Marshall S., Evaluation of the Safety Analysis Report for the Waste Isolation Pilot Plant Project, May 1985.

EEG-30 Dougherty, Frank, Tenera Corporation, Evaluation of the Waste Isolation Pilot Plant Classification of Systems. Structures and Components, July 1985.

EEG-31 Ramey, Dan, Chemistry of the Rustler Fluids, July 1985.

EEG-32 Chaturvedi, Lokesh and James K. Channell, The Rustler Formation as a Transport Medium for Contaminated Groundwater, December 1985.

EEG-33 Channell, James K., John C. Rodgers, Robert H. Neill, Adequacy of TRUPACT-I Design for Transporting Contact-Handled Transuranic Wastes to WIPP. June 1986.

EEG-34 Chaturvedi, Lokesh, (ed.), The Rustler Formation at the WIPP Site, Report of a Workshop on the Geology and Hydrology of the Rustler Formation as it Relates to the WIPP Project, February 1987.

EEG-35 Chapman, Jenny B., Stable Isotopes in Southeastern New Mexico Groundwater: Implications for Dating Recharge in the WIPP Area, October 1986.

EEG-36 Lowenstein, Tim K., Post Burial Alteration of the Permian Rustler Formation Evaporites, WIPP Site, New Mexico, April 1987.

EEG-37 Rodgers, John C., Exhaust Stack Monitoring Issues at the Waste Isolation Pilot Plant, November 1987.

EEG-38 Rodgers, John C. and Jim W. Kenney, A Critical Assessment of Continuous Air Monitoring Systems at the Waste Isolation Pilot Plant, March 1988. 


\section{LIST OF EEG REPORTS (continued)}

EEG-39 Chapman, Jenny B., Chemical and Radiochemical Characteristics of Groundwater in the Culebra Dolomite, Southeastern New Mexico, March 1988.

EEG-40 Review of the Final Safety Analyses Report (Draft). DOE Waste Isolation Pilot Plant, December 1988, May 1989.

EEG-41 Review of the Draft Supplement Environmental Impact Statement, DOE Waste Isolation Pilot Plant, July 1989.

EEG-42 Chaturvedi, Lokesh, Evaluation of the DOE Plans for Radioactive Experiments and Operational Demonstration at WIPP, September 1989.

EEG-43 Kenney, Jim W., John Rodgers, Jenny Chapman, Kevin Shenk, Preoperational Radiation Surveillance of the WIPP Project by EEG 1985-1988, January 1990.

EEG-44 Greenfield, Moses A., Probabilities of a Catastrophic Waste Hoist Accident at the Waste Isolation Pilot Plant, January 1990.

EEG-45 Silva, Matthew K., Preliminary Investigation into the Explosion Potential of Volatile Organic Compounds in WIPP CH-TRU Waste, June 1990.

EEG-46 Gallegos, Anthony F. and James K. Channell, Risk Analysis of the Transport of Contact Handled Transuranic (CH-TRU) Wastes to WIPP Along Selected Highway Routes in New Mexico Using RADTRAN IV, August 1990.

EEG-47 Kenney, Jim W. and Sally C. Ballard, Preoperational Radiation Surveillance of the WIPP Project by EEG During 1989, December 1990.

EEG-48 Silva, Matthew, An Assessment of the Flammability and Explosion Potential of Transuranic Waste, June 1991.

EEG-49 Kenney, Jim, Preoperational Radiation Surveillance of the WIPP Project by EEG During 1990 November 1991.

EEG-50 Silva, Matthew K. and James K. Channell, Implications of Oil and Gas Leases at the WIPP on Compliance with EPA TRU Waste Disposal Standards, June 1992.

EEG-51 Kenney, Jim W., Preoperational Radiation Surveillance of the WIPP Project by EEG During 1991. October 1992.

EEG-52 Bartlett, William T., An Evaluation of Air Effluent and Workplace Radioactivity Monitoring at the Waste Isolation Pilot Plant, February 1993.

EEG-53 Greenfield, Moses A. and Thomas J. Sargent, A Probabilistic Analysis of a Catastrophic Transuranic Waste Hoist Accident at the WIPP, June 1993.

EEG-54 Kenney, Jim W., Preoperational Radiation Surveillance of the WIPP Project by EEG During 1992. February 1994.

EEG-55 Silva, Matthew K., Implications of the Presence of Petroleum Resources on the Integrity of the WIPP, June 1994.

EEG-56 Silva, Matthew K. and Robert H. Neill, Unresolved Issues for the Disposal of Remote-Handled Transuranic Waste in the Waste isolation Pilot Plant, September 1994. 


\section{LIST OF EEG REPORTS (continued)}

EEG-57 Lee, William W.-L, Lokesh Chaturvedi, Matthew K. Silva, Ruth Weiner, and Robert H. Neill, $\underline{\text { An }}$ Appraisal of the 1992 Preliminary Performance Assessment for the Waste Isolation Pilot Plant. September 1994.

EEG-58 Kenney, Jim W., Paula S. Downes, Donald H. Gray, Sally C. Ballard, Radionuclide Baseline in Soil Near Project Gnome and the Waste Isolation Pilot Plant. June 1995.

EEG-59 Greenfield, Moses A. and Thomas J. Sargent, An Analysis of the Annual Probability of Failure of the Waste Hoist Brake System at the Waste Isolation Pilot Plant (WIPP), November 1995.

EEG-60 Bartlett, William T. and Ben A. Walker, The Influence of Salt Aerosol on Alpha Radiation Detection by WIPP Continuous Air Monitors, January 1996.

EEG-61 Neill, Robert, Lokesh Chaturvedi, William W.-L. Lee, Thomas M. Clemo, Matthew K. Silva, Jim W. Kenney, William T. Bartlett, and Ben A. Walker, Review of the WIPP Draft Application to Show Compliance with EPA Transuranic Waste Disposal Standards, March 1996.

EEG-62 Silva, Matthew K., Fluid Injection for Salt Water Disposal and Enhanced Oil Recovery as a Potential Problem for the WIPP: Proceedings of a June 1995 Workshop and Analysis, August 1996.

EEG-63 Maleki, Hamid and Lokesh Chaturvedi, Stability Evaluation of the Panel 1 Rooms and the E140 Drift at WIPP, August 1996.

EEG-64 Neill, Robert H., James K. Channell, Peter Spiegler, Lokesh Chaturvedi, Review of the Draft Supplement to the WIPP Environmental Impact Statement, DOE/EIS-0026-S-2, April 1997.

EEG-65 Greenfield, Moses A. and Thomas J. Sargent, Probability of Failure of the Waste Hoist Brake System at the Waste Isolation Pilot Plant (WIPP) January 1998.

EEG-66 Channell, James K. and Robert H. Neill, Individual Radiation Doses From Transuranic Waste Brought to the Surface by Human Intrusion at the WIPP February 1998.

EEG-67 Kenney, Jim W., Donald H. Gray, and Sally C. Ballard, Preoperational Radiation Surveillance of the WIPP Project by EEG During 1993 Though 1995, March 1998.

EEG-68 Neill, Robert H., Lokesh Chaturvedi, Dale F. Rucker, Matthew K. Silva, Ben A. Walker, James K. Channell, Thomas M. Clemo, Evaluation of the WIPP Project's Compliance with the EPA Radiation Protection Standards for Disposal of Transuranic Waste, March 1998.

EEG-69 Rucker, Dale, Sensitivity Analysis of Performance Parameters Used In Modeling the Waste Isolation Pilot Plant, May 1998.

EEG-70 Bartlett, William T. and Jim W. Kenney, EEG Observations of the March 1998 WIPP Operational Readiness Review Audit, May 1998.

EEG-71 Maleki, Hamid, Mine Stability Evaluation of Panel 1 During Waste Emplacement Operations at WIPP. July 1998.

EEG-72 Channell, James K. and Robert H. Neill, A Comparison of the Risks from the Hazardous Waste and Radioactive Waste Portions of the WIPP Inventory, July 1999.

EEG-73 Kenney, Jim W., Donald H. Gray, Sally C. Ballard, and Lokesh Chaturvedi, Preoperational Radiation Surveillance of the WIPP Project by EEG from 1996 - 1998, October 1999. 


\section{LIST OF EEG REPORTS (continued)}

EEG-74 Greenfield, Moses A. and Thomas J. Sargent, Probability of Failure of the TRUDOCK Crane System at the Waste Isolation Pilot Plant (WIPP) May 2000.

EEG-75 Channell, James K. and Ben A. Walker, Evaluation of Risks and Waste Characterization Requirements for the Transuranic Waste Emplaced in WIPP During 1999, May 2000. 